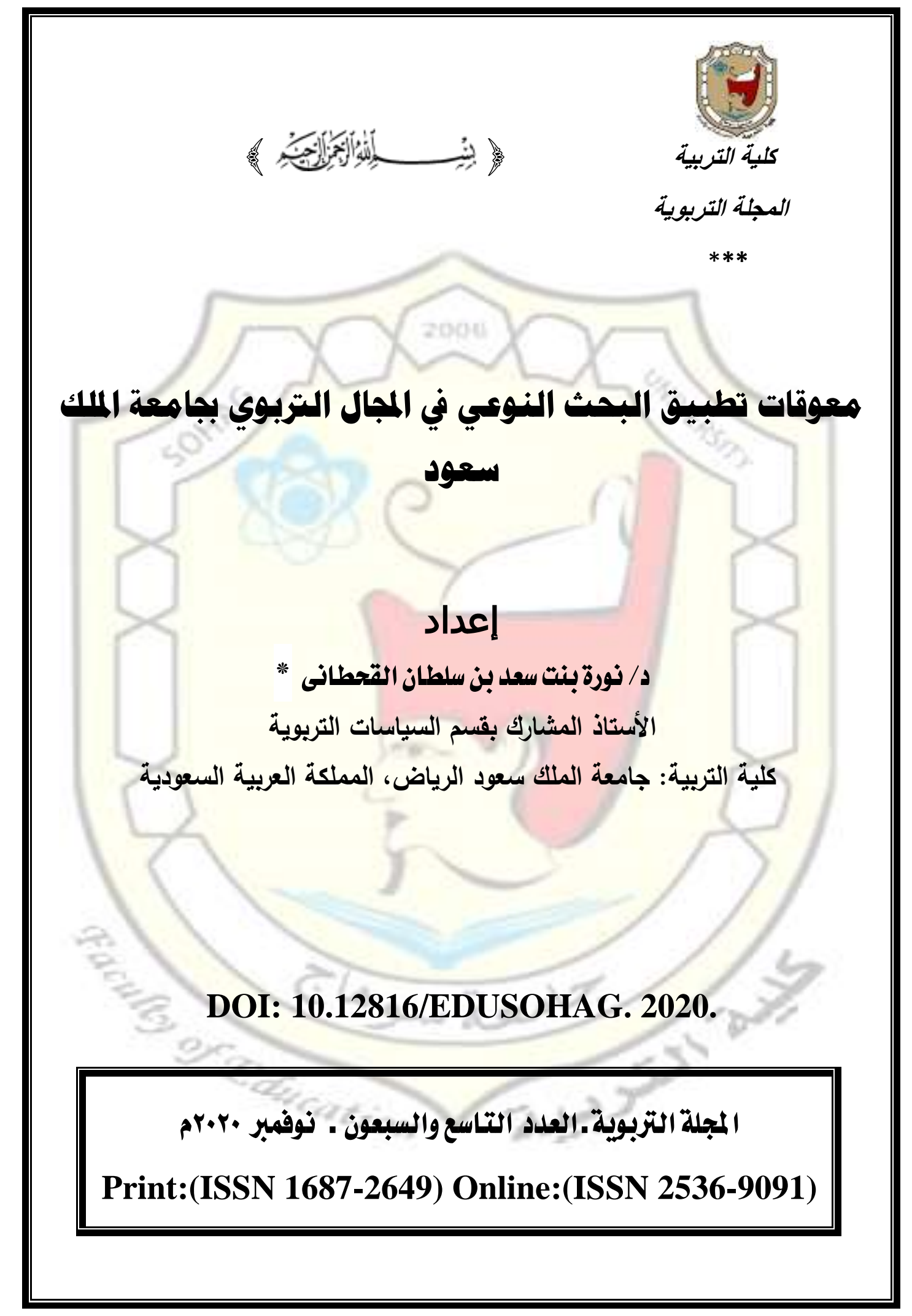


المستخلص:

هدفت هذه الاراسة إلى الكثف عن أهم معوقات تطبيق الباحثين أعضاء هيئة التدريس في كلية التربية بجامعة الملك سعود للبحث النوعي في المجال التريوي، كما وهدفت إلى الكثف عن الفروق الدالة إحصائيا إن وجدت في استجابة العينة تعزى لمتغيري الجنس

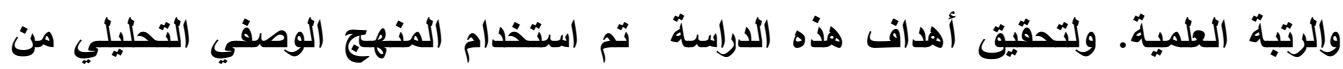

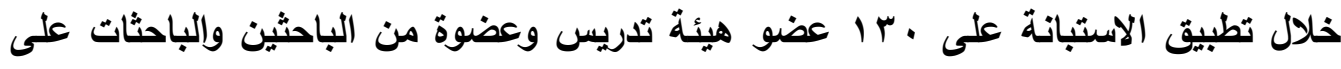

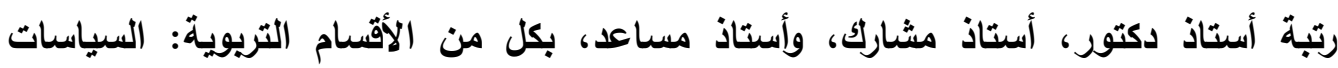

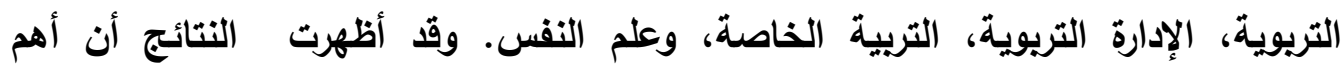
المعوقات التي حصلت على استجابة العينة بدرجة كبيرة جدا هي: نفسية، تدريبية، مهارية، وميدانية، كما وأظهرت فروقا دالة إحصائيا في استجابة العينة لصالح الذكور، ولأصحاب الرتبة العلمية الأقل. ويناءً على النتائج قدمت الاراسة مجموعة من التوصيات، وطرحت عدة مقترحات.

الكلمات المفتاحية: معوقات، البحث النوعي، الباحثين، أعضاء هيئة التدريس، المجال

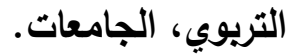




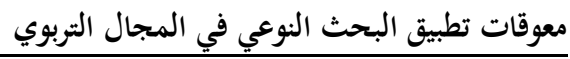

Obstacles to applying qualitative research in the educational field at King Saud University

Norah Saad Sultan Al-Qahtani**

Associate Professor, Department of Educational Policies, College of

Education, King Saud University

\begin{abstract}
:
This study aimed to uncover the most important obstacles to the application of researchers, faculty members in the College of Education at King Saud University, to qualitative research in the educational field. It also aimed to uncover statistically significant differences, if any, in the response of the sample due to the variables of sex and academic rank. To achieve the objectives of this study, the descriptive and analytical approach was used by applying the questionnaire to 130 faculty members of the researchers at the rank of professor, associate professor, and assistant professor, in each of the educational departments: educational policies, educational administration, special education, and psychology. The results showed that the most important obstacles that got to the sample response to a very large extent are: psychological, training, skill, and field, and they showed statistically significant differences in the response of the sample in favor of males and those with a lower academic rank. Based on the results, the study presented a set of recommendations and made several proposals.
\end{abstract}

Key words: Obstacles, qualitative research, researchers, faculty members, the educational field, universities.

** Riyadh, Saudi Arabia, P.O. Box (76075), Postal Code:( $1 / 9 r$ r) 


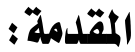

إن المصدر الرئيسي في الوصول إلى معرفة صادقة وموثوقة هو البحث العلمي، الذي تزايد استخدامه بشكل واضح في صنع القرارات، وحل المشكلات في مختلف حقول

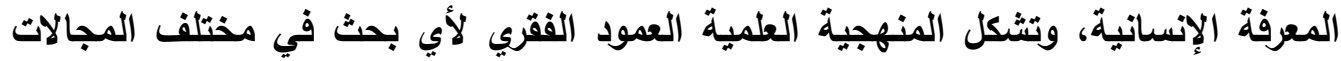
وإلعلوم بما فيها أبحاث العلوم الإنسانية والاجتماعية، وذلكك باستخدام أساليب وإجراءات

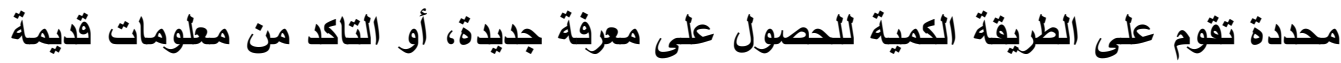
من أجل زيادة المعرفة أو التحقق منها. ولقد ظهرت في السنوات الأخيرة أساليب غير كمية في البحث العلمي، جذبت كثيرا

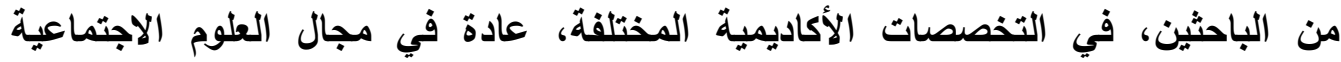

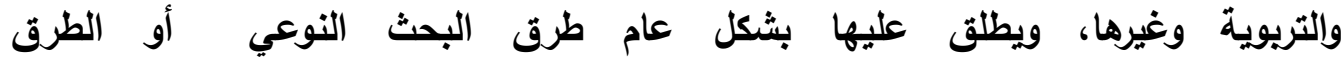
النوعية Qualitative methods، التي لا تستند على النماذج الرياضية، بل إلى نماذج وصفية سلوكية تساهم بشكل ويآخر في معالجة المشكلات في الواقع العملي للمؤسسات

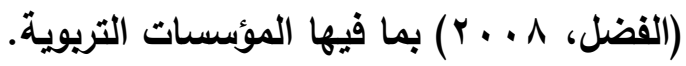
وتقوم مناهج البحث النوعي على معتقات وأغراض مختلفة عن تلك التي تتؤمن بها

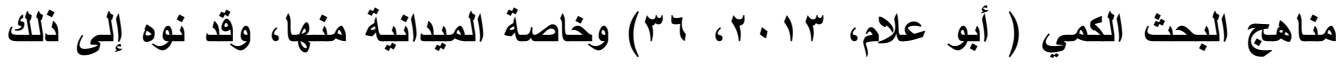
كريس ويل (Creswell) مشيرا إلى أن مناهج البحث النوعي الميداني تركز على أهمية رأي أفراد عينة البحث المشاركين، والتأكيد على الموقف الذي يطبق فيه البحث، وفهم وتصوير المعنى الذي يينيه المشاركون في هذا الموقق بعينه (Creswell, 2005)، دون محاولة الباحث التلاعب بالأحداث والمشاهد الاجتماعية والعمليات أو السيطرة عليها في الميدان (أبو لوات

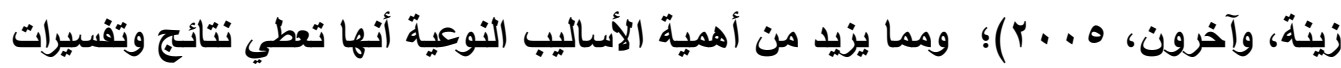

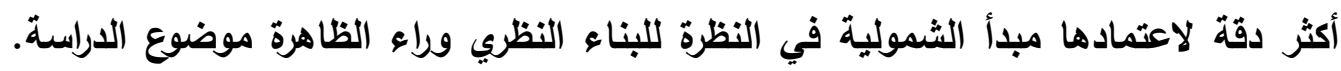

$$
\text { (عبيدات، ... (r) }
$$

وقد تنامى قبول هذا التوجه في البحث، خاصة في المجال التربوي، نتيجة لتضاؤل

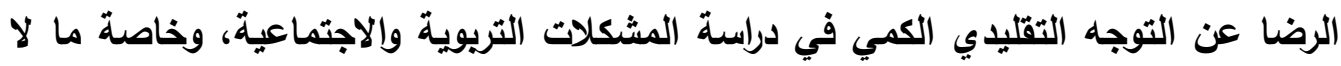
يتناسب منها مع التحليل الكمي، ولما تتميز به البحوث النوعية من القدرة على تمكين الباحث من الحصول على المعرفة المباشرة عن الواقع الاجتماعي والتربوي الذي يتناوله بالدراسة، 
وتزويده بالفهم الكامل لهذا الواقع (Zikmund,2000)، وتقديم نظرة ثاقبة لقضايا التعليم والتعلم وفهم عميق وأفضل لطبيعة المشكلات التريوية في عدد من السياقات الطبيعية (Anderson, 2010)، والمساهمة في التوصل إلى نتائج قد تقود إلى حلول ومعالجات

لهذه القضايا والمشكلات. (Erickson, 1986)

\section{تُحليد المشكانة}

على الرغم من أن كثيرا من الدراسات أوصت بالتوسع في استخدام منهجية البحث النوعي، والتوجه نحو الاعتماد على الأساليب النوعية والإستفادة منها في دراسة الظواهر والمشكلات التي تتميز بالتعقيد، بلالا من الاعتماد على المنهج الكمي في إجراء دراساتهم،

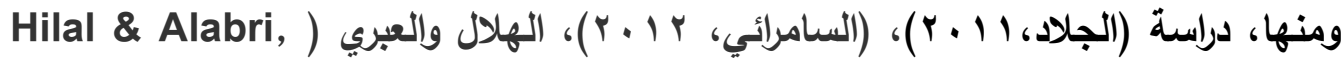

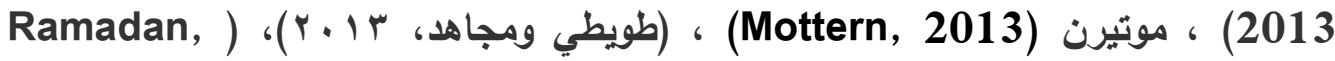

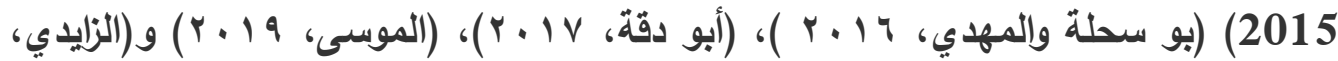
$\cdot(r \cdot 19$

ومع أن "منهج البحث التريوي يؤكد تأكيدا بالغا على ضرورة استخدام مناهج بحث متعددة ووسائل متنوعة لتغطية مشكلة الدراسة من أبعادها وزواياها المختلفة"

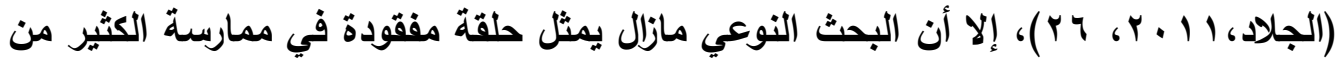

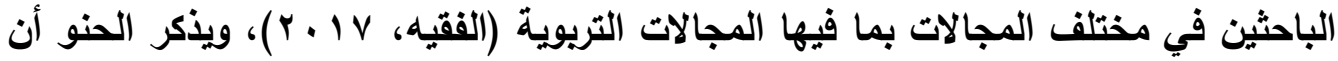
مستوى استخدامات المنهج النوعي وتطبيقاته في البحوث التريوية وصل إلى مستوى الندرة من قبل الباحثين العرب في المجال التريوي ( الحنو، 1 ـ ـ ) )، وفي ذات السياق، أثشار القحطاني إلى أن كثيرا من الجامعات العربية تعيش ركودا كبيرا فيما يتعلق بتوظيف المنهج

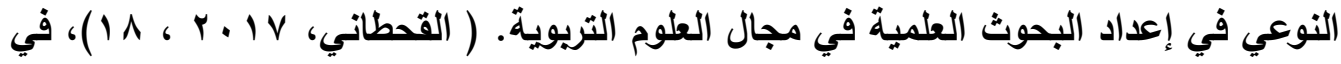

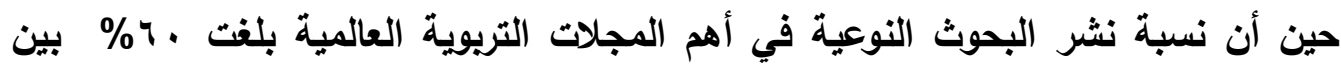

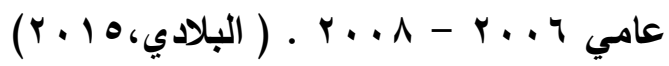

وحيث أن البحث النوعي الميداني يعد أحد أهم أنواع البحث التربوي التي لا غنى

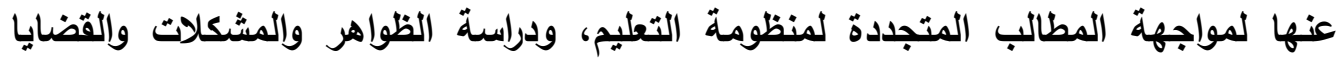
التربوية في سياقها الطبيعي، وتقديم فهم معقد يستتد على حقائق متعددة ووجهات نظر مختلفة، ومعالجة عميقة لها، وصوغ الحلول والقرارات التي يقود تبنيها نحو تطوير الأداء 
التريوي، وضمان قوة وفاعلية المؤسسات التريوية في ظل عالم متغير، جاعت هذه الدراسة للكشف عن معوقات تطبيقه في المجال التريوي بجامعة الملك سعود.

تساؤلات اللدراسة

جاءت الدراسة الحالية لتجيب على التساؤلين الآتيين:

ا ـ ما أهم معوقات تطبيق البحث النوعي في المجال التريوي من وجهة نظر أعضاء هيئة

$$
\text { التدريس في كلية التربية بجامعة الملك سعود ؟ }
$$

r. هل توجد فروق ذات دلالة إحصائية في استجابة عينة الدراسة حول هذه المعوقات تعزى

لمتغيري الجنس والرتبة العلمية؟

أهداف الدراسة

هدفت هذه الدراسة إلى:

1. الكشف عن أهم معوقات تطبيق البحث النوعي في المجال التريوي من وجهة نظر أعضاء الهيئة التدريسية في كلية التربية بجامعة الملك سعود. r ـ التعرف على الفروق ذات الدلالة الإحصائية - إن وجلت - في استجابات عينة الدراسة حول هذه المعوقات تعزى لمتغيري الجنس والرتبة العلمية.

أهمية الدراسة

تأتي أهمية الدراسة من عدة اعتبارات تظهر في الأهمية النظرية والتطبيقية، وهي على النحو الآتي: الأهمية النظرية النية - - أهمية البحوث النوعية ودورها في تفسير عميق وشامل للظاهرة التربوية في سياقها الطبيعي. - - ندرة الدراسات التي تتناول أهم المعوقات التي تحول دون تطبيق البحث النوعي في المجال التربوي من وجهة نظر أعضاء هيئة التدريس بكلية التربية التابعة للأقسام الإنسانية في جامعة الملك سعود. - الإضافة المتواضعة للمكتبة العربية، وفتح المجال للباحثين من أعضاء هيئة التدريس بدراسة شبيهة في أقسام كلية التربية بالجامعات السعودية. أما الأهمية التطبيقية فتظهر في: 
- - نتائج الدراسة التي تقلم للمعنين وواضعي السياسات وصناع القرار بجامعة الملك سعود واقعا لهذه المعوقات التي تحول دون تطبيق أعضاء هيئة التذريس للبحث

$$
\text { النوعي في المجال التربوي. }
$$

- توصيات الدراسة التي قد يستتير بها عمادة البحث العلمي بكلية التربية بجامعة الملك سعود، للعمل على تذليل هذه المعوقات بوضع الخطط الاقيقة والاستراتيجيات الموضوعية التي من شأنها أن تعزز بشكل واسع من انتهاج الباحثين من أعضاء هيئة التدريس بكلية التربية أو الجامعة للبحث النوعي في تناول القضايا التريوية

في سياقها الطبيعي.

حدود الدراسة

تمثلت حدود الدراسة في:

الحدود الموضوعية: اقتصرت على كشف أهم المعوقات التي تحول دون تطبيق

أعضاء الهيئة التدريسية لبحث النوعي في المجال التريوي، وكثف الفروقات الدالة إحصائيا إن وجلت في استجابة عينة الدراسة حول هذه المعوقات تعزى لمتغيري الجنس والرتبة العلمية.

الحدود البشرية: تم تطبيق الدراسة على أعضاء هيئة التدريس (ذكور/إناث) ذوي

$$
\text { الرتب العلمية (أستاذ/ استاذ مشارك/ أستاذ مساعد). }
$$

الحدود المكانية: اقتصر تطبيق الدراسة على أعضاء الهيئة التدريسية في أربعة

أقسام أكاديمية تابعة لكلية التربية بجامعة الملك سعود هي ( السياسات التربوية، الإدارة التريوية، التربية الخاصة، وعلم النفس،). الحدود الزمانية: تم تطبيق الاراسة في الفصل الدراسي الثاني من العام الجامعي

$$
\begin{aligned}
& \left.\cdot p^{r} \cdot r \cdot \Delta\right) \leq 1 \\
& \text { مصطاحات اللدراسة } \\
& \text { المعوقات اصطلاحا }
\end{aligned}
$$

يعرف قاموس ويبستر المعوقات بانها "العثرات والأشياء التي تقف وتحول دون التقدم".

(Webster, 1999, 415) 


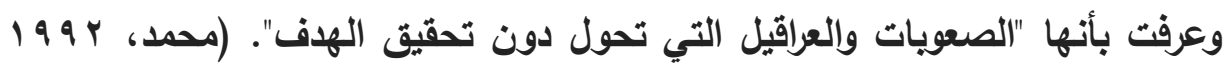

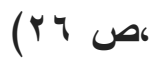

كما وعرف المعوق بأنه "ذلك الثيء العسر الذي يثكل صعوية، ويعرقل تحقيق

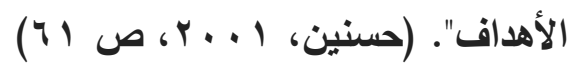

أما الهلالات فيعرف المعوقات بأنها الحيلولة دون تحقيق الهذف، والمنع عن ذلكاني

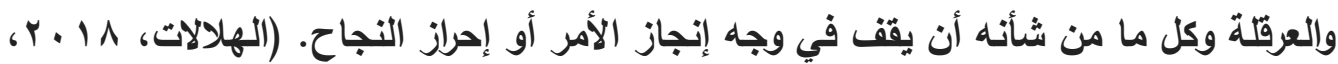

(9

وتعرف الدارسة الحالية المعوقات بأنها الصعويات والعقبات التي تحول دون تطبيق

أعضاء هيئة التدريس للبحث النوعي في المجال التريوي.

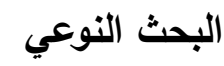

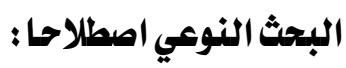

يقصد بمصطلح البحث النوعي أنه "توع من البحوث العلمية التي تفترض وجود

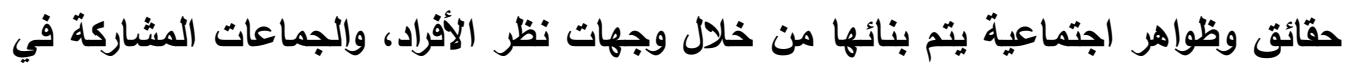

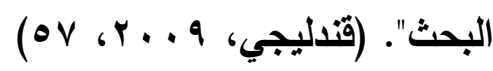

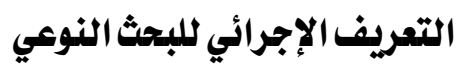
تعرف الدارسة البحث النوعي إجرائيا بأنه: نوع من البحوث الكيفية التي تدرس

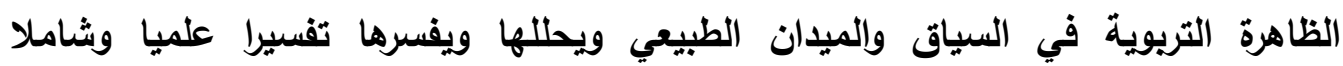
باستخدام أدوات نوعية غير كمية مثل الملاحظة بالمشاركة، المقابلة، والوثائق.

المجال التربوي

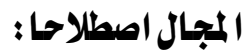

يقصد بمصطح المجال أنه "الحقل، أو الميدان الذي يتم فيه العمل" (الثريفي، ( $90,4 \ldots$

التعريف الإجرائي للمجال التزبوي

تعرف الدراسة المجال التريوي إجرائيا بأنه : الحقل أو الميدان الذي تتم فيه

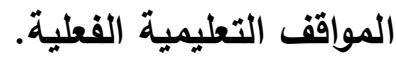


الإطظار النظري

إضاءات على نشاة وتطور البحوث النوعية

على الرغم من أن الأصول التاريخية لنشأة المنهج النوعي ترجع إلى إسهامات علوم الأنثرويولوجيا في أواخر القرن الثامن عشر وأوائل القرن التاسع عشر، إلا الاستخدام

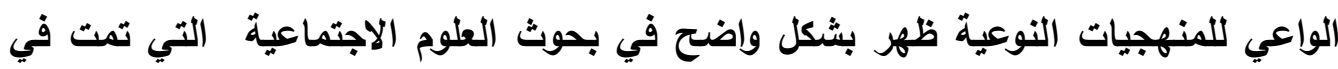
الثثلاثينيات والأريعينيات من القرن العشرين الماضي. (Taylor \& Bogdan,1984)

(Guba \& Lincolin,1988)

وفي ستينيات القرن العشرين طالب الباحثون باستخدام البحوث النوعية كبديل جديد

عن البحوث الكمية التقليدية (Guba \& Lincolin,1988)، وأكد المنظور الأساسي للبحوث النوعية كشكل جديد يعالج نواحي القصور في الطرق البحثية التقليدية على أهمية

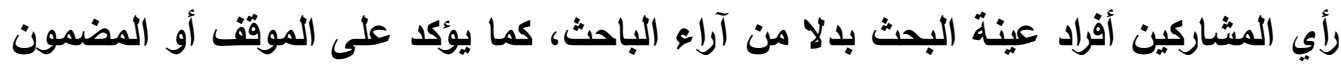

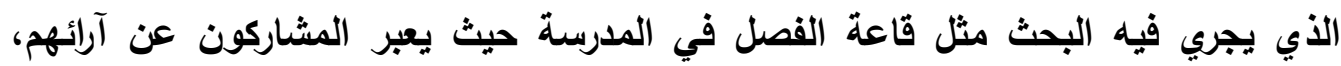
ويؤكدون على المعنى الأي يحصل عليه الناس من القضايا الاجتماعية المختلفة.

(Creswell,2005)

وفي العقد الأخير من القرن العشرين ظهرت أفكار جديدة في البحوث النوعية تتعلق بممارسات المشاركة دعت إلى إضافة المشاعر الثخصية للباحثين النوعيين وقيمهر وآرائهم في تقارير بحوثهم النوعية التي يقومون بها، وأكلات عند جمع البيانات النوعية على التى الاهتمام بمشاعر المشاركين والتعاون معهم بفاعلية، بلالا من مجرد دراستهم، واحترام كرامة لهونة

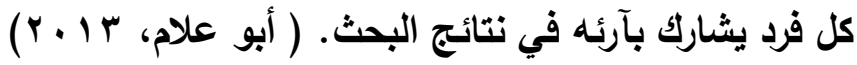

تعريف البحث النوعي

بالرغم من أهمية ما تقدمه البحوث الكمية من طرح للمشكلة البحثية ووضعها في صيغة أرقام وإحصائيات لقياس وحصر القضايا ثم تعميم النتائج على نطاق بشري أوسع، إلا ماند أن البحوث الكيفية / النوعية تظل لها أهمية كبيرة في فهم وتفسير المشكلات المرتبطة بالبشر؛ وذلك لأن هدف البحوث الكيفية هو الحصول على فهم مفصل للأسباب والمعتقدات، والدوافع الخاصة بالمشكلة البحثية. كما تهدف إلى فهم لماذا وكيف وما التاأثيرات والسياقات 


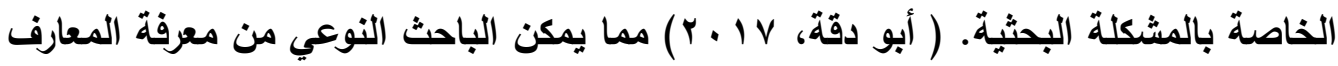
والمهارات والمواقف المتعلقة بالظاهرة المدروسة. (Hilal \& Alabri,2013) ولقد اتخذ البحث النوعي عدة مسميات منها: البحث الطبيعي، لأنه يهنم بدراسة الظواهر في سياقها الطبيعي، وقد يسمى البحث التفسيري، لأنه لا يكتفي بالوصف فقط بل

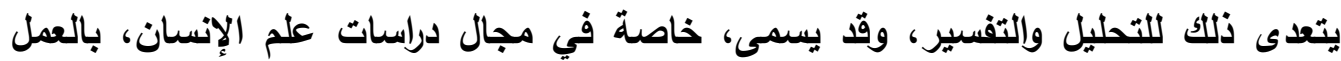

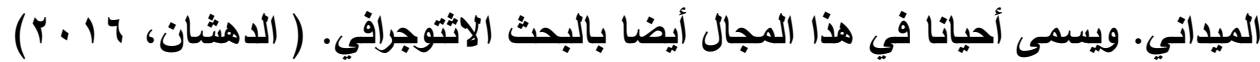

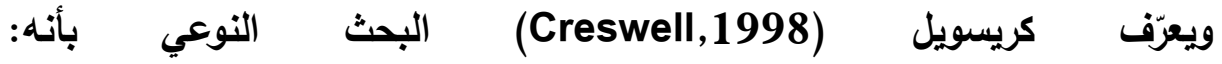
"عمليةٌ تحقيق للفهم، مستندة على التقاليا المُتميّزة لمنهج البحث العلمي التي تقوم بالكثف عن مشكلة اجتماعية أو إنسانية. ويقوم الباحث ببناء صورة معقدة وشمولية ويُحلّلُ الكلمات، ويضع تقريرا يفصّل فيه وجهات نظر المرشدين ثم يقوم بإجراء الدراسة في الموقف الطبيعي ". (Creswell,1998,15) وعرفت البحوث النوعية بأنها تلكك البحوث الكيفية التي تهتم بالقهم والتفسير المتعق للأحداث والظواهر من كافة أبعادها في السياق أو الموقف الطبيعي وعلاقتها بالأحداث وإلظواهر الأخرى، مستخدمة في ذلك أساليب غير كمية في جمع المعلومات كالتعبيرات الرمزية وإلكلمات، والصور، ثم تحليل هذه المعلومات بطريقة استقرائية مع التركيز على المعاني التي يذكرها المشاركون، ووصف العملية بلغة معبرة مقتعة بالحجة والبراهين.

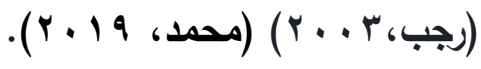

الأسس الفلسفية للبحوث النومية

يرتكز كل عمل بحثي إلى أساس فلسفي، ويرتبط هذا الأساس بطريقة النظر إلى المعرفة، ويالمنهجيات المناسبة التي تستخدم في البحوث، وعليه يستلزم إجراء البحوث الكيفية أو التفسيرية فهم المنطلق الفلسفي أو النموذج الذي تستند إليه، لأن ذلك بدوره يحدد الأساليب المنهجية التي يعتمدها الباحث (Crotty,1998) وتقوم فلسفة البحث النوعي على أن هناك أكثر من واقع، ولا توجد حقيقة أو معرفة واحدة ثابتة كما هو الحال في البحث الكمي، وإنما هنالك أكثر من حقيقة يتم دراستها وفهمها في سياقها الطبيعي، ويناؤها من وجهات نظر مختلفة. (الزايدي، 1 ـ ب ) 
التصاميم الشائعة لمنهجيات البحث النوعي

يذكر كريسويل (Creswell,2007) أن هناك خمسة تصاميم شائعة للبحوث

النوعية ترتبط بالاختلافات الأساسية لأهداف المنهجيات النوعية. وتعد حسب آري وأخرون (Ary \& Others, 2010)

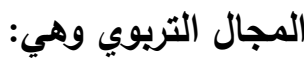
1. دراسة الحالة study Case: تهدف إلى التعرف على خصائص الشخص، أو الجماعة، أو المنظمة، أو الأحداث التي يجري عليها البحث حول المشكلة المدروسة. r. الإثنوجرافيا Ethnography: تهتم بتحديد ثقافة ووجهات نظر مجموعة من الناس في سياقها الطبيعي حول المشكلة المدروسة. r. السرد القصصي Narrative inquiry : ويجيب عن السؤال ما رأي وفهم وخبرة المشاركين عن المشكلة المدروسةمن خلال دراسة قصص من حياتهم حولها. ع. دراسة الظواهر Phenomenological study: تركز على كيف يواجه المشاركون المشكلة المدروسة ويتعاملون معها. ه. النظرية المؤسسة / المتجذرة Grounded Theory: تركز على تحديد النظرية التي يمكن التوصل إليها استقرائيا عن المشكلة المدروسة من خلال البيانات التي سوف

$$
\text { تجمع من سياقها. }
$$

وتعتمد النظرية في البحوث النوعية على مجموعة من البناءات والافتراضات المترابطة التي توضح العلاقات القائمة بين عدد من المتفيرات، وتهذف إلى تفسير ظاهرة

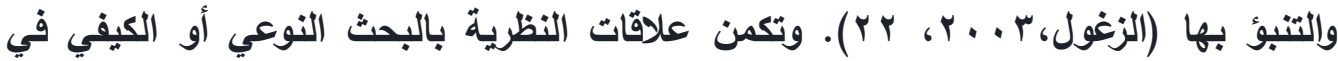

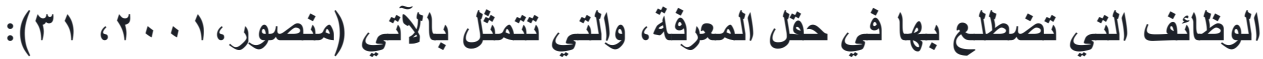
ا ـ تعمل على تجميع الحقائق وترتيبها في بناء منظم منسق مما يجعل منها ذات معنى وقيمة.

r. تقدم توضيحاً وتفسيراً لعدد من الظواهر والأحداث الطبيعية والإنسانية والكونية. r. تساعد في التنبؤ بالعديد من الظواهر وتوقع حدوثها أو عدمه في ظل معطيات ومؤشرات 
4. توجه الفكر العلمي، فهي بمثابة الموجه لإجراءات وعمليات البحث العلمي والاستدلال العقلي.

طرق جمع البيانات في البحث النوعي في البحوث النوعية يجمع الباحث أنواعا متعددة من البيانات، وقد يضيف استمارات جديدة لجمع البيانات أثناء القيام بالدراسة. وينهمك الباحث في جمع بيانات مكثفة، ويقضي فترة طويلة من الوقت في الموقع الذي يعمل فيه الناس أو يقومون فيه بأنشطة

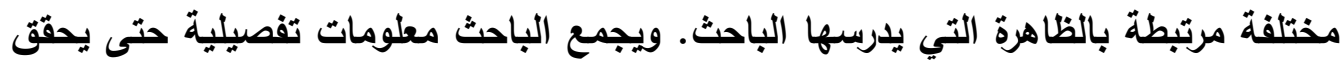

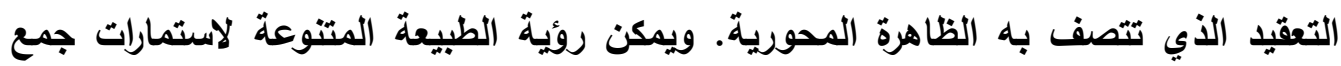
البيانات في البحث النوعي عند تصنيفها في عدة أشكال، هي: الملاحظات، المقابلات،

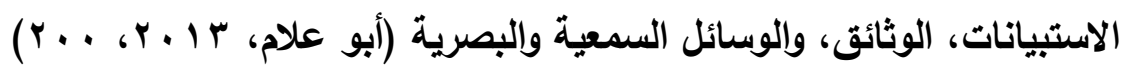

ولقد فتحت تكنولوجيات الاتصال الجديدة الطريق لاستخدام أساليب وتقتيات جديدة

ومبتكرة ومتعددة لجمع البيانات في البحوث النوعية سواء للباحثين ذوي الخبرة أو المبتدئين، ومناسبة ومتزامنة لمختلف المشاركين وظروفهم، دون التقليل من جودة هذه البحوث. وتتمثل تكنولوجيا الاتصالات الجديدة هذه في: المقابلات الإكترونية عبر الإنترنت (المقابلات بالبريد

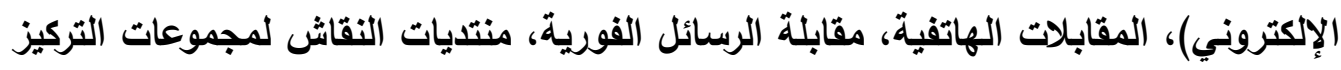
أو المجموعات البؤرية على الإنترنت، منتديات الحوار الإكتروني، ومقابلات الصوت عبر بروتوكول الإنترنت ، ومقابلات السكايب، ورسائل الدردشة النصية على تويتر والفيسبوك . (Amirav, 2014)

\section{مزايـا استخدام وتطبيق البحوث النوعية}

يشبه دنسكومب (Denscombe,2010) البحوث النوعية بالشعلة، إذ أن الشعلة إذا قُربت من شيء ما، فيمكن روئة مساحة صغيرة بتفصيل كبير، ويالمقابل إذا وُضِعت بعيدا عن شيء ما، فسوف تغطي مساحة أكبر، ولكن لا يمكن الحصول على القدر ذاته من

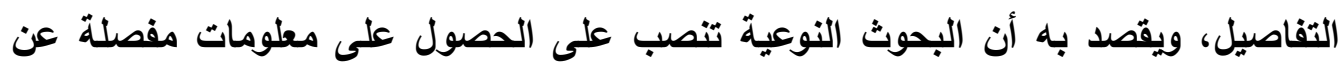
عدد صغير من العينات، ولا تسعى هذه البحوث إلى التوصل إلى تعميمات حول أعداد كبيرة

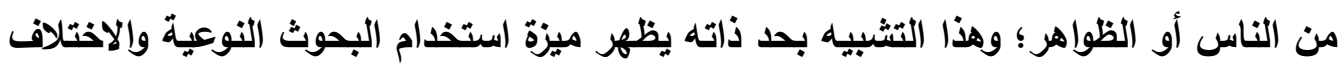
بينها ويين اسخدامات البحوث الكمية. 
ويضيف دنسكومب (Denscombe,2010) أن البحوث النوعية عادة تركز على الكلمات و/أو الصور، بدلا من التركيز على الأرقام، ويذلك يتفوق تصميم البحوث النوعية على تصميم البحوث الكمية من حيث الاهتمام بالأشخاص الذين يحاول الباحث تمثيل تجاريهم.

ويذكر باتثيرجي أن للبحوث النوعية مزايا فريدة تحتوي عليها هي: أولا، تعتبر هذه

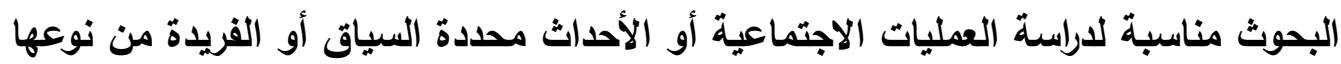

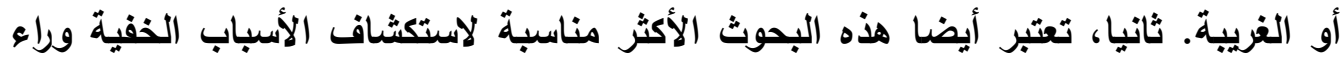

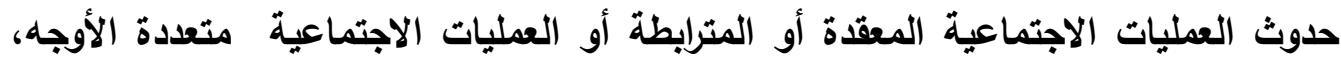
ثالثا: تعتبر هذه البحوث في أغلب الأحيان من البحوث المفيدة بالنسبة إلى بناء النظرية في المجالات التي لا توجد بها نظريات سابقة أو أن تكون تلك النظريات غير كافية. رابعا، يمكن أن تساعد البحوث النوعية أيضا في الكثف عن أسئلة البحث المثيرة للاهتمام أو الأسئلة

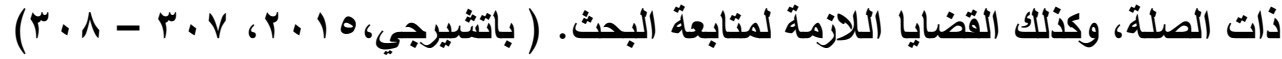
ويضيف رويرت (Robert,2011) أن من مميزات البحوث النوعية: دراسة معاني حياة الناس في ظروفها وسياقها الطبيعي، وتقديم وإظهار روئية الناس ووجهة نظرهم، وتغطية الظروف في السياقات الطبيعية التي يعيش فيها الناس، وتقديم رؤى قد تساعد على تفسير سلوك الإنسان الاجتماعي، والسعي لاستخدام مصادر متعددة للاليل بدلا من الاعتماد على لئي لئي مصدر وحيد.

ويعبارة أخرى، يقر النهج البحثي النوعي بتنوع وجهات النظر، ويتفوق كتصميم على تصميم البحوث الكمية من حيث الاهتمام بالثخاص الذين بحاول الباحث تمثيل تجاربهم. وهذا ما ذكره كريسويل (Creswell,2007) بأن البحث النوعي يركز على التعرف على

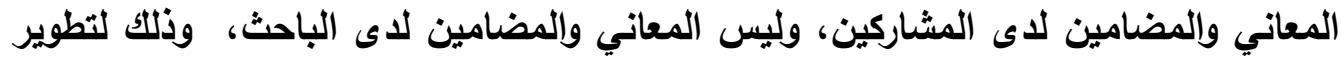
وعرض صورة واضحة للمشكلة أو الظاهرة المدروسة من خلال تقديم وجهات النظر المتعددة للمشاركين بطريقة منظمة ومترابطة. ويستعرض الاليل المرجعي للباحثين الكيفيين في فصله الحادي عشر الصادر من مركز البحوث الاجتماعية بالجامعة الأمريكية بالقاهرة، أن من فوائد واستخدام البحث الكيفي تمتع الباحث الكيفي بفرصة التقرب والتعرف على عينة الدراسة وما يخلقه ذلك من علاقات 
دينامية بين المشارك والباحث مبنية على أساس الثقة والصراحة والتبادل. (دليل مرجعي

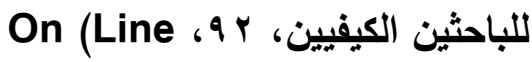

\section{معوقات استخلام وتطبيق البحوث النوعية/ نقاط الضعف الكامنة في البحوث النوعية}

مع أهمية وضرورة البحوث النوعية لاسيما في العلوم الإنسانية والاجتماعية والتقتية المعاصرة، إلا أن إدواردز (Edwards, 2010) يحذر من الاعتقاد بأن البحوث النوعية خيار

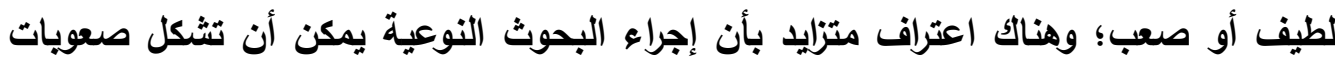
كثيرة للباحثين (Swift V. Dickson, et al, 2007) ، ومنها حسب (محمد، 9 19. Y)،

$$
\text { ^ }
$$

- احتياج الباحث النوعي إلى قضاء فترات طويلة في الميدان الطبيعي لجمع البيانات مع الإثارة إلى ضرورة تواجده بنفسه، أو مع باحثين مساعدين له.

- يتطلب البحث النوعي مهارات عالية وإمكانات قد لا تتوفر في كثير من الباحثين؛ إذ أن الباحث النوعي هو الأداة الأساسية لجمع البيانات من خلال: المقابلات والمشاهدات

$$
\text { الميدانية. }
$$

- معايير الصدق والموضوعية يصعب توفيرها في كثير من الحالات في البحوث النوعية بنفس الارجة التي تتوافر فيها في البحوث الكمية.

- تكلفة المنهج النوعي عالية، حيث يتطلب إجراء البحوث النوعية من الباحث أن يقوم بالانتقال من مكان لآخر، ولأكثر من مرة.

- عدم قدرة الباحث على مواصلة البحث، بسبب بعد الظروف، الأمر الذي يجعل إلمامه بكافة الظروف أمرا مستحيلا.

ومن صعويات تطبيق البحث النوعي كما ذكرها أبو علام الكم الهائل والدقيق من البيانات الذي يتطلب من الباحث النوعي تدوينها خلال فترة زمنية طويلة، بالإضافة إلى

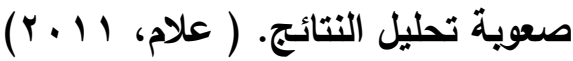
ويؤخذ على البحوث النوعية صعوية تعميم النتائج المتولدة عنها على الحالات المشابهة، وفي ذلك يذكر دنسكومب (Denscombe,2010) أن تركيز البحوث النوعية يكون على الحصول على معلومات مفصلة عن عدد صغير من العينات في معظم الأحيان، ولا تسعى هذه البحوث إلى التوصل إلى تعميمات حول أعداد كبيرة من الناس أو الظواهر. 
كما أنها تتهم بعدم الموضوعية، بمعنى أن كمية وجودة البيانات وعمق التحليل، كل هذه الأمور تعتمد على قدرة الباحث على التحليل والاستتباط والقيام بكل ذلك بموضوعية ( التل،

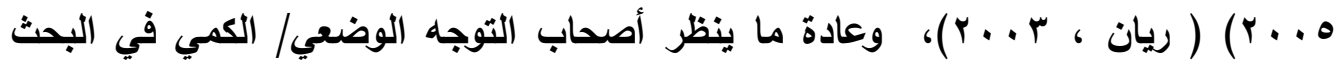
للأساليب النوعية بأنها ليست كفيلة في المقام الأول بتحقيق العلمية والموضوعية ( بوسحلة

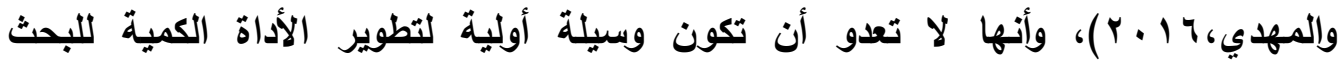

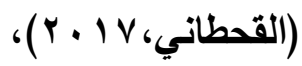

كما يواجه الباحثون المنتمون للنموذج الكيفي منذ لحظة دخول الحقل وحتى الانتهاء من العمل الميداني العديد من التحديات والمعوقات غير المسبوقة؛ ولذلك، قد لا يتمكن الباحث من الاحتفاظ بتحكمه في عملية البحث في كافة الأوقات ـ وحتى الباحث المتمكن يتعرض لمواجهة المشاكل، بالرغم من استعداده ومهاراته، وصعوية التحكم بالمتحدثين المهيمنين على الجلسة في مجموعات النقاش البؤرية، وصعوية محافظة الباحث على الحياد والموضوعية في علاقته بالمشاركين، إلى جانب صعوية العمل مع فريق من الباحثين يمثلون

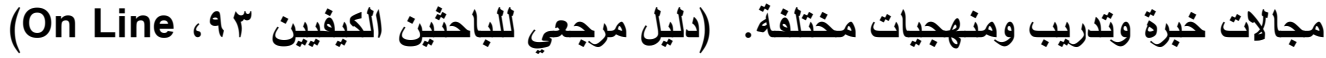
ويضيف حجر(r r . . أن البحث الكيفي يعاني من قصور شديد من جانب الباحثين

فيما يتعلق بوسائله وإجراءاته ومناهجه، ، وإفتقاره للصدق والثبات، والخلل المنهجي، وضعف ماتف الصرامة العلمية، والوقوع في خطأ الملاحظات الانتقائية أو التدوين الانتقائي

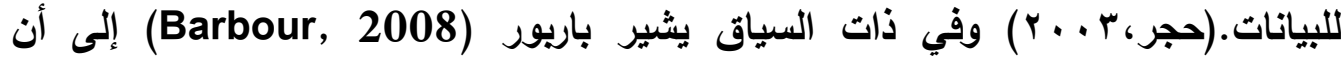
البحوث النوعية تقِّ بأهمية ذات الباحث عند إعداد البحوث، ويكيفية تأثثر هذه الذات على بلى البحث، فضلا عن كيفية تأثير البحث نفسه على الباحث، وتسىى هذه العلاقة بين ذات Fine, ) الباحث والبحث النوعي بالعلاقة الإنعكاسية؛ وفي ذات السياق يقول فاين وآخرون (et al,2000,108): " توجد نزعة منذ زمن بعيد لاعتبار ذات الملاحظ في مجال العلوم الاجتماعية سببا لإفساد البحث، ولذلك ينبغي فصل هذه الذات عن البحث، وتحييدها، والتقليل من تأثيره ومعايرتها، وضبطها". ويؤكد أليسون على أن البحوث النوعية تحتاج إلى مزيد من الصرامة العلمية في إعداد التقارير النوعية. (Alizon, 2004)، ويقصد بالصرامة العلمية في البحوث النوعية كما يوضحها صوان، الدقة، والمصداقية، وقابلية النقل (الملاعمة)، والاعتمادية (قابلية 
التوثيق)، وقابلية التثبت، والجودة. ويضيف صوان أن عدم اختيار الباحث للأدوات الاقيقة لجمع البيانات النوعية والمناسبة لأسئلة البحث سبب في ظهور الخلل المنهجي (صوان،

كما ويذكر باتثيرجي أن البحوث التفسيرية/ النوعية تمتلك مجموعة من التحديات

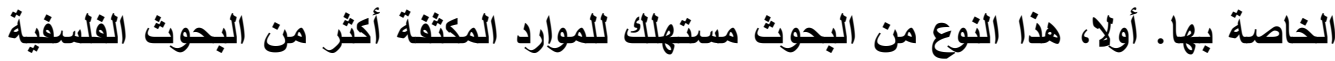
أو الوضعية في كل من عملية جمع البيانات والجهود التحليلية. ثانيا، تتطلب هذه البحوث البهائ وجود باحثين على أعلى مستوى من التدريب ممن يكونوا قادرين على روئة وتفسير الظاهرة الاجتماعية / التريوية المعقدة من التصورات الخاصة بالمشاركين والعمل على التوفيق والجمع لئح بين التصورات المتنوعة والمختلفة الخاصة بهوّلاء المشاركين دون تدخل من التحيزات الثخصية أو التصورات المسبقة الخاصة بهم في هذه الاستنتاجات. ثالثا، عدم كفاية الثقة

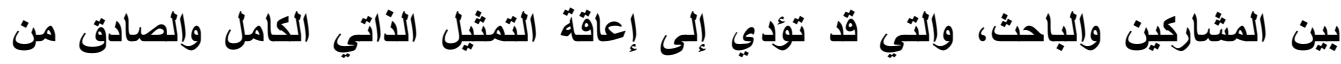

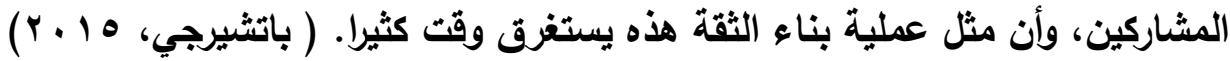

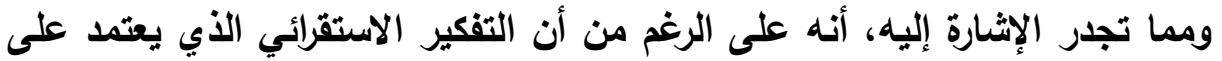

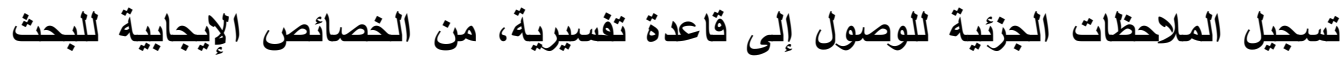

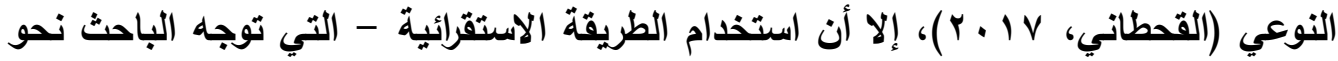
موضوع معين دون تكوين تصورات راسخة حوله أو افتراضية، تتعلق بأي من المتغيرات وكيفية الريط والعلاقة بينهما - من المعوقات والصعويات التي تواجه الباحثين عند تطبيق التهني

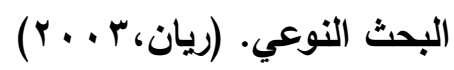

ويضيف كل من جيل وإليزابيث (Gill \& Elizabeth, 2014) أن من الصعويات الميدانية التي قد تواجه الباحثين عند تطبيق البحوث النوعية، عدم الكفاءة والخبرة القليلة أو الو الفيات

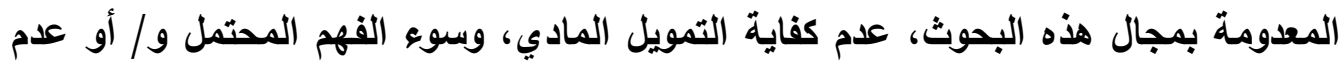
الثقة بين الباحث والمشاركين، ومشاعر عدم اليقين، والإجهاد والإرهاق جراء المكوث لفتراء الفترات طويلة لجمع البيانات والذي قد يدفع الباحث لترك البحث وعدام إكماله. 
الدراسات السابقة

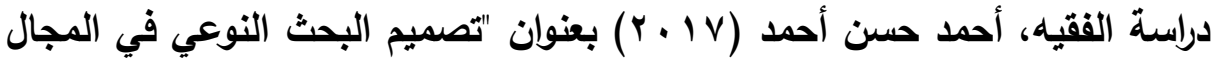

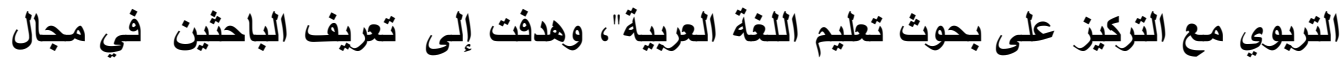
تعليم اللغة العربية بالخلفية الفلسفية للبحث النوعي، ومفهوم وخصائص البحث النوعي، بالإضافة إلى كيفية تصميم البحث النوعي في بحوث تعليم وتعلم اللغة العربية. وكثفت نتائج الدارسة عن أن الباحثين في مجال تعليم اللغة ما زالوا يعتمدون في دراسة قضايا ومشكلالت تطليمها على مناهج البحث الكمي، نظرا لأن مجموعة منهم تنقصه المعارف والمهارات والخبرات المتصلة بالبحث النوعي واستخداماته. دراسة الزايدي، ضيف الله بن عواض (9 (19) بعنوان "معوقات استخدام المنهج الكيفي في بحوث الإدارة والقيادة التريوية من وجهة نظر أعضاء هيئة التدريس بالجامعات السعودية"، وهدفت إلى تعرف المعوقات التي تواجه استخدام المنهج الكيفي في بحوث الإدارة والقيادة التريوية من وجهة نظر أعضاءهيئة التدريس بالجامعات السعودية. استخدمت التهاته الدراسة المنهج المختلط وتم استخدام الاستبانة والمقابلة لجمع البيانات، حيث تكونت عينة الدارة من (1 (1) عضو هيئة تدريس في الجامعات السعودية من المتخصصين في مجال

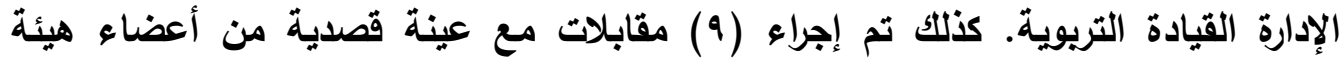
التدريس في الجامعات السعودية. وقد أظهرت نتائج الدراسة أن معوقات استخدام المنهج الكيفي في بحوث الإدارة والقيادة التريوية جاءت بدرجة متوسطة ويمتوسط حسابي قدات التره

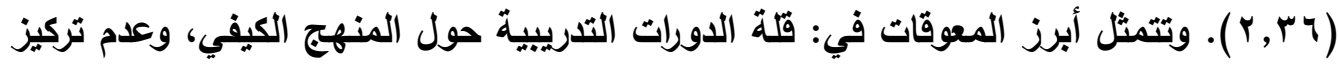
برامج الدراسات العليا على المنهج الكيفي بالقدر الكافي مقارنة بالمنهج الكمي، ومقاومة الكادية

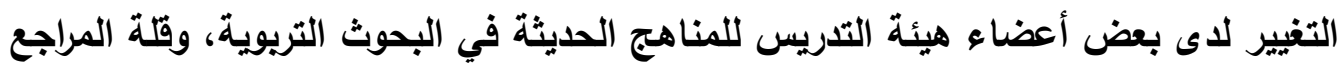
المترجمة إلى العربية حول مناهج البحث الكيفي، وعلم القتاعة بأهمية المنهج الكيفي في البحث التربوي وكذلك توصلت الدراسة إلى وجود فروق ذات دلالة إحصائية عند مستوى دلالة

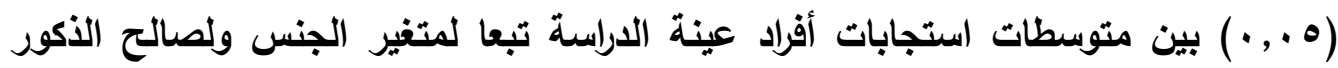
وعدم وجود فروق ذات دلالة إحصائية عند مستوى (ه, •) بين متوسطات استجابات أفراد عينة الدراسة تبعا لمتغير الرتبة العلمية والجامعة. 
دراسة الموسى، أسماء إبراهيم (9 ( ب ب) بعنوان "تفعيل البحث الكيفي في تخصص أصول التربية بالجامعات السعودية في ضوء الخبرات العالمية المعاصرة"، وهدفت الدراسة إلى بهي تقديم تصور مقترح لتفعيل البحث الكيفي في تخصص أصول التربية بالجامعات السعودية في ضوء الخبرات العالمية المعاصرة بناءً على تثخيص واقع البحث الكيفي في تخصص أصول التربية بالجامعات السعودية، والكشف عن المعوقات التي تحول دون تفعيله، بالإضافة إلى تحليل أبرز الخبرات العالمية المعاصرة في مجال العلوم الكيفية. اعتمدت الدراسة في منهجها التصميم المختلط، وطبقت أداة المقابلة على (r I ) أستاذ من أعضاء هيئة التدريس تخصص مله أصول التربية بالجامعات السعودية، ووزعت الاستبانة على (1 • 1) عضوا من أعضاء هيئة التدريس بالجامعات السعودية تخصص أصول التربية. وخرجت الاراسة بأهم النتائج وكان من الن التهن أبرز النتائج المتعلقة بأعضاء هيئة التدريس ندرة الخبراء المتخصصين في البحث الكيفي بالجامعات السعودية، تفضيل الأستاذ الجامعي استخدام أنماط البحث الكمي المتعارف عليها، وضعف قناعة الأستاذ الجامعي بجدوى البحث الكيفي التريوي. دراسة الحنو، إبراهيم عبدالله (T 1 • Y) بعنوان "مدى استخدام منهجية البحث النوعي في التربية الخاصة: دراسة تحليلية لعشر مجلات عربية محكمة في الفترة من هـ ـ. . إلى ؛ 1 ـ Y"، وهدفت الدراسة إلى التعرف على مدى استخدام منهجية البحث النوعي في ميدان التربية الخاصة من خلال تحليل البحوث المنشورة في عشر مجلات عربية علمية محكمة

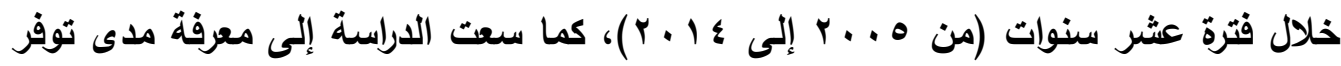
مؤشرات الجودة في الأبحاث النوعية التي تم العثور عليها. بلغ عدد أبحاث التربية الخاصة

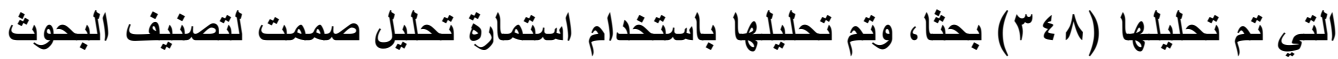
إلى بحوث نوعية وكمية، ونظرية ومختلطة. وكثفت نتائج الدراسة أنه تم استخدام منهجية البحث النوعي في (r) دراسات فقط وينسبة († ^, • \%)، في حين استخدمت منهجية البحث

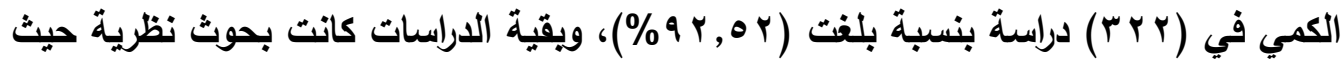

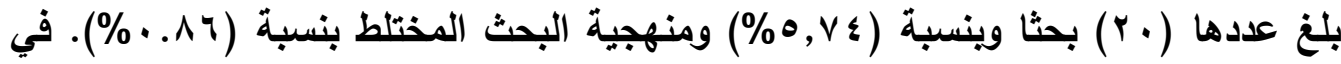
المرحلة الثانية من الدراسة، تم إخضاع الدراسات النوعية التي تم العثور عليها لتحليل إضافي لمعرفة مدى توفر مؤثرات الجودة فيها وأثارت نتائج التقييم أن البحوث النوعية الثلاثة توفر فيها مؤثرات الجودة المتعارف عليها في البحث النوعي. بينت نتائج الدراسة 
بوضوح أن البحوث النوعية نادرا ما تستخدم من قبل الباحثين العرب في التربية الخاصة وهذا قد يكون دلالة على وجود صعوية في تقبل طريقة البحث النوعي في إجراء البحوث والحصول على المعرفة بالرغم من مناسبته لدراسة قضايا ومواضيع التربية الخاصة.

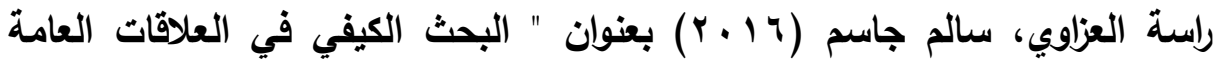

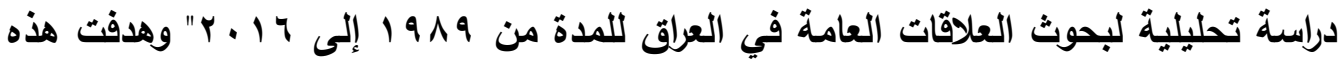

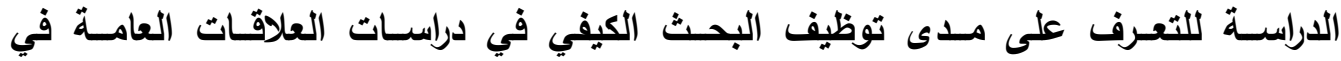

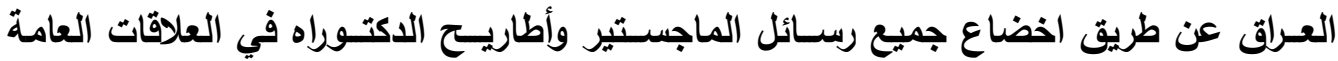

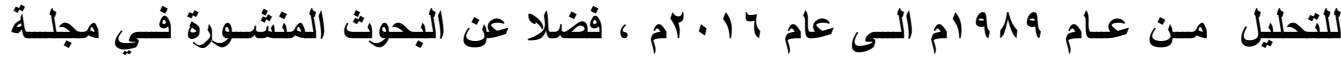
الباحث العالمي وهـي المجلة العراقية الوحيدة المعنبـة بالبحوث العالمية وتصدر عـن كلية

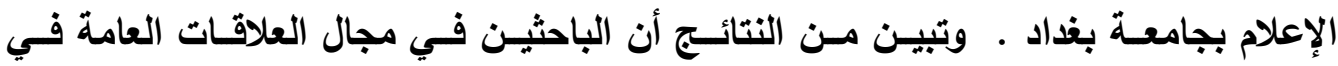

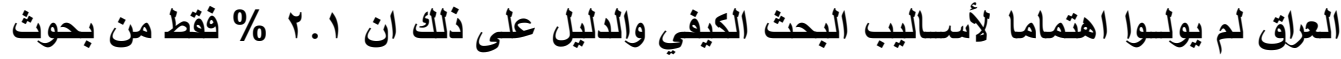

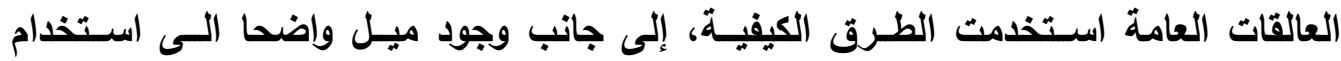

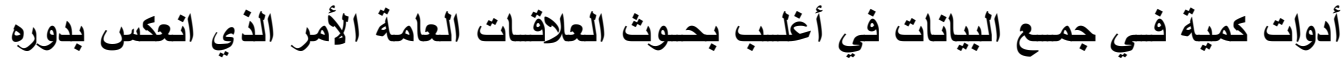

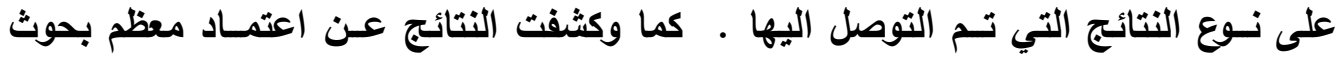
العلاقات العامة على دراسـة المبحوثين بطريقة المعاينة أو نظـام الحصـر الثــامل، واعتماد ثلث البحوث تقريبـا على طريقة تحليل المحتـوى. دراسة ديكسون وآخرون (Dickson \& Others, 2007) بعنوان "إجراء بحوث حساسة: ما التحديات التي تواجه الباحثين النوعيين؟" وهدفت إلى استكثاف المثكلات التي تواجه البحوث الصحية. وقد تم تطبيق هذه الدراسة على (·r) من الباحثين في مجال الصحة باستخدام المقابلات الفردية معهم. وكثف تحليل النتائج إلى أن الباحثين يمكنه

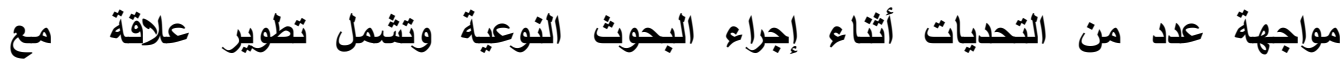

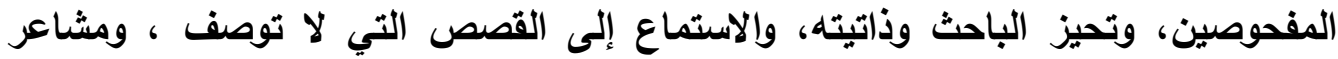
الأنب والضعف ، وترك البحث وعدم إكماله، واستنفاد طاقة وجها الباحث. دراسة خانكة، حميد (Khankeh \& Others,2015) بعنوان " التحديات في إجراء البحوث النوعية في مجال الصحة: ورقة مفاهيمية". استهافت الدراسة الكثف عن العن التحديات العملية لاستخلام البحث النوعي في مجال الصحة. ولتحقيق هاف التهاء الدراسة تم 


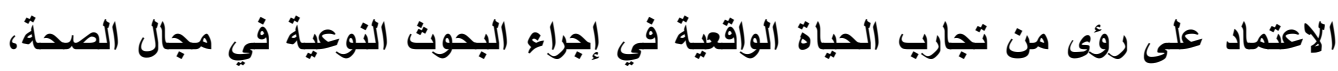

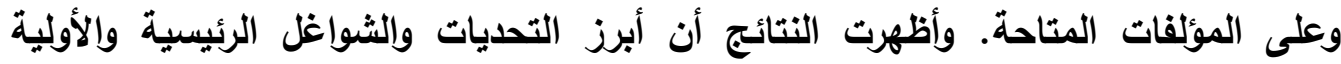

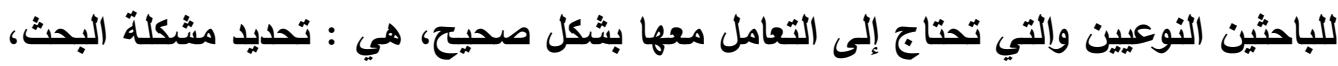
تثكيل السؤال والهدف من البحث، اختيار المنهجية وتصميم البحث المناسبين، عدم الاتساق بين سؤال البحث والمنهجية، عدم كفاية المعرفة المنهجية، وعدم الاهتمام بالأسس الفلسفية للمنهجية النوعية. كما وكثفت النتائج أن هذه التحديات التي يواجهها الباحثون تكون شائعة بشكل خاص عند المبتائين، وفي المراحل الأولى من أي مشروع بحثي. دراسة وانق (Wang,2013) بعنوان "تحديات تطلم كتابة البحوث النوعية" وكان الغرض منها هو استكشاف التحديات وأنماط الصعويات التي يواجهها الباحثون المبتدئون عند تطبيق البحث النوعي لأول مرة. طبقت الدراسة على (؛) طلاب باحثين مستعينة

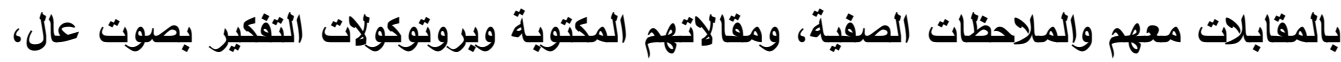
وكان من أبرز النتائج: تدني مستوى الممارسة التدريجية في عملية تحليل البيانات النوعية، ضعف مهارة تحليل البيانات النوعية بصورة منهجية وشاملة وذلك لغموض وصعوية عملية تحليل البيانات النوعية، استغراق عملية التحليل إلى وقت طويل، الذاتية في تفسير البيانات النوعية، وضعف مهارة تفسير النتائج بثكل جدلي ومقتع يستثل إلى وجود الحجة الواضحة والأدلة.

دراسة وولز (Walls, 2011) بعنوان " التحديات الاجتماعية والثقافية في إجراء

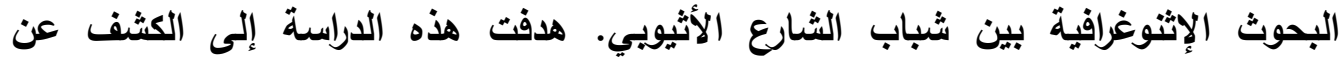

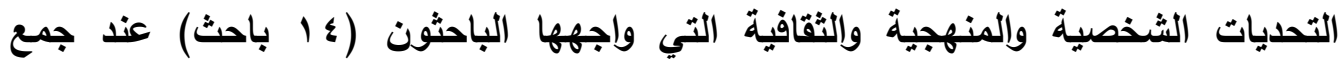
البيانات النوعية باستخدام التثليث من شباب الثوارع في أديس أبابا بأثيوبيا. وتوصلت نتائج

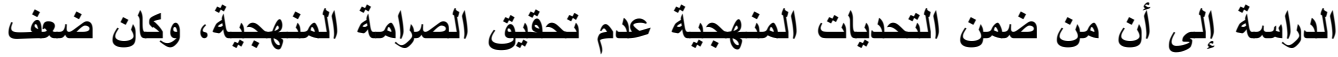

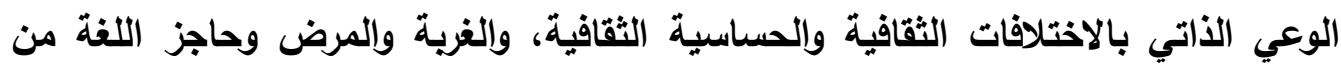
أبرز التحديات الثقافية والثخصية التي واجهها الباحثون أثناء تطبيق الدراسة. دراسة ألكسندروس وآخرون (Alexandros \& Others, 2012) وعنوانها" فهم تحديات البحث النوعي: القضايا البيانية والعملية". الغرض من ورقة العمل هذه تقديم نظرة ثاقبة للصعويات التي تواجه تطبيق الباحثين للبحث النوعي في مجال التسويق من وجهة نظر الترائ 
ورؤى الباحثين وتجاريهم الميدانية. وكان من أبرز التحديات التي توصلت لها الورقة غموض معايير تحليل البيانات النوعية، وضخامة كمية البيانات النوعية.

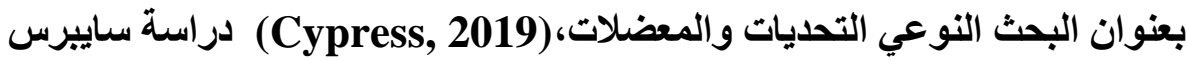
وهدفت إلى إلقاء الضوء على التحديات والمعضلات التي تواجه الباحثين من طلاب الدكتوراه اثثاء تطبيق البحث النوعي، وكان من أبرز هذه التحديات كما كشفت عنها النتائج صعوية اختيار الموضوع، صعوية اختيار المنهجية وتصميم البحث، وصعوية جمع الكم الكبير من البيانات النوعية وإدارتها وتحليلها. ) بعنوان " التحديات الأخلاقية من Abedini \& Others, 2019 عابديني وآخرون (وجهة نظر الطلاب في العلوم الطبية: دراسة نوعية مع نهج تحليل المحتوى" .واستهدفت هذه الدراسة استكشاف تصور الطلاب للتحديات الأخلاقية التعليمية. طبقت الاراسة مقابلات فربية متعقة وجها لوجه وشبه منظمة على عينة قوامها ( • ؛ ) طالب طالبة من جامعة العلوم الطبية في هرمزجان في مجالات الطب والتمريض ... وطب الأسنان والصيلةل. وتم إجراء تحليل للبيانات النوعية في وقت واحد مع جمع البيانات باستخدام تحليل المحتوى النوعي مع النهج الاستقرائي. وأثشارت نتائج الاراسة أن الطلاب يواجهون تحديات أكاديمية وتواصلية ومهنية في مجال التعليم تؤثر على القيم الأخلاقية في التعليم الطبي، فكاتت من بين التحديات العلمية والأكاديمية التي يواجهها الطلاب شح المادة العلمية، وغلبة العلوم النظرية غير العملية، والتقييمات غير القياسية. ويالنسبة للتحديات التواصلية فكاتت المعاملة غير العادلة ، والأحكام الجائرة ، وعدم التعاطف معهم في شؤون التواصل، والفجوة

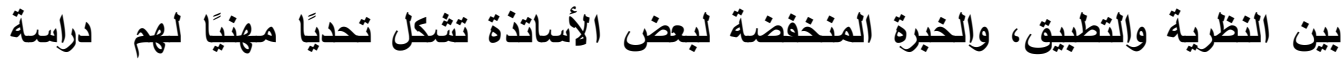

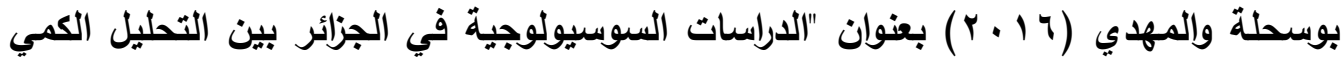
والكيفي"، وسعت لتحقيق عدة أهداف منها التعرف على أسباب عزوف الباحثين عن استخدام المنهج الكيفي في الدراسات السوسيولوجية المعاصرة. اعتمدت الدراسة على منهج البحث الميداني، وطبقت باستخدام المقابلة على عينة قدر حجمها بعشرة مبحوثين من الأساتذة الباحثين ذوي الخبرة في التدريس في كلية العلوم الاجتماعية والإنسانية والإشراف على مذكرات التخرج، وخرجت بعدة نتائج منها ما يتعلق بالهرف السالف الأكر، وهي: عدم الإلمام بكيفية استخدام المناهج الكيفية وطرقها، الخوف من عدم تحقى الموضوعية في البحث الذي 


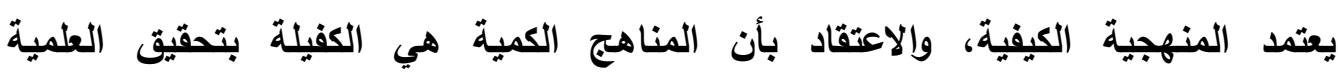
والموضوعية نتيجة لما توفره للباحث من قدرة على التحكم في أبعاد الدراسة التي يقوم بها. دراسة رمضان (Ramadhan,2015) بعنوان " تحديات البحث النوعي: هل يمكن استخدامه لتعزيز عملية صنع القزار في الرعاية الصحية بأوغندا"، وهافت إلى تحديد بعض

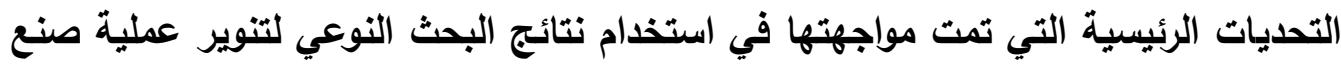
القرار السياسي، بالاستناد على مراجعة الأدبيات. واستخدمت الاراسة المنهج الوصفي التحليلي. وتوصلت إلى أن سيطرة أنصار المنهج الكمي على المواقع القيادية في قطاع الإدات الصحة بأوغندا، وعدم اقتناعهم بالبحوث الكيفية تعتبر تحدي يواجه استخدام المنهج الكيفي. وتوصي الدراسة بضرورة دعم استخدام المنهج الكيفي ودراسة الظاهرة في سياقها الاجتماعي. (Queiros, A; Faria, D \& Almeida, F, دراسة جورس وفاريا وأمليدا (2017وعنوانها " نقاط القوة والقيود على طرق البحث النوعي والكمي " ، وهدفت إلى التعرف على نقاط القوة والتحديات للمنهجين الكيفي والكمي. واستخدمت الدراسة المنهج المقارن للمقارنة بين نقاط القوة والتحديات في المنهجين. وتوصلت الدراسة إلى عدة نتائج، ركزت

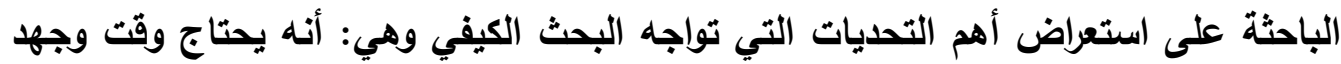
كبيرين في جمع البيانات وتحليلها، وصعوية تعميم النتائج، وضرورة مراعاة القضايا الأخلاقية بعناية فائقة، وصعوية الحصول على العينة وتمثيلها لمجتمع الدراسة.

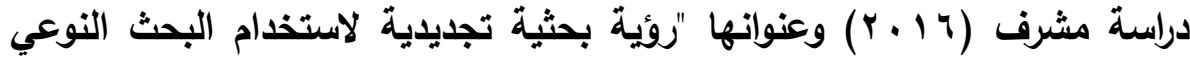
في معالجة بعض جوانب أزمة البحث التريوي" ، وهدفت إلى التعرف على معالم الروئية التجايدية التى تتبنى استخدام البحث النوعي في معالجة بعض جوانب أزمة البحث التريوي، وأهم التحديات التي تواجه تطبيق منهجية البحث النوعي في مجال البحث التريوي.

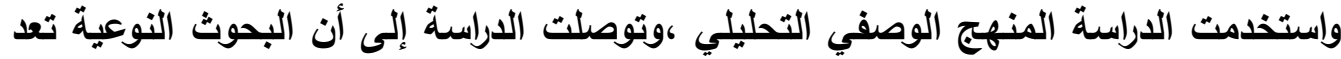

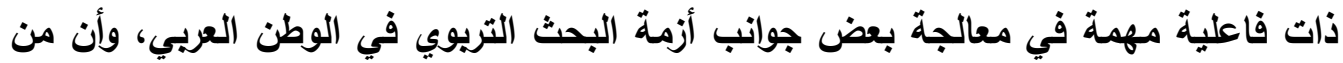

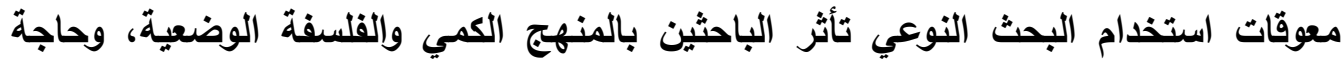
الباحثين إلى التدريب على استخدام البحث الكيفي وطرقه وأدواته وتحليل بياناته، والوقت والجها الكبير الذي يحتاجه البحث النوعي في جمع البيانات وتحليلها وتفسير النتائج،

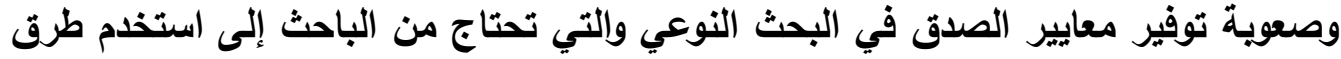




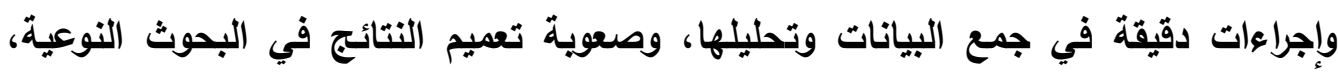
وعدم ثقة بعض أنصار المنهج الكمي بالبحوث النوعية.

أوجه الاستفادة من الدراسات السابقة استفادت الدراسة الحالية من الدراسات السابقة في تحديد المشكلة، والأهداف، وإثراء الإطار النظري، وتصميم ويناء أداة الدراسة.

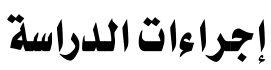

منهج الدراسة

اعتمدت الباحثة في هذه الدراسة على المنهج الوصفي التحليلي بهدف وصف الظاهرة ثم تحليلها بناء على ما تم جمعه من معلومات حول الظاهرة. ويعرف بأنه المنهج

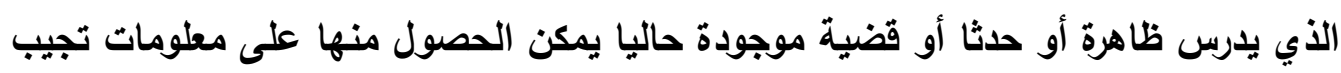

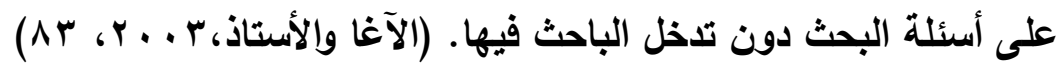

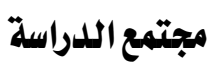
تمثل المتمع الأصلي في جميع أعضاء الهيئة التدريسية الذكور والإناث من ذوي

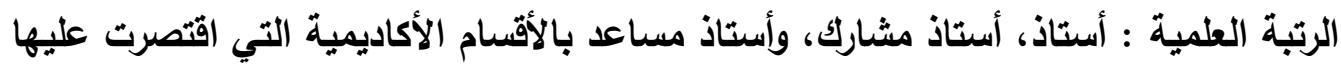
الدراسة والتتابعة لكلية التربية بجامعة الملكك سعود وهي: السياسات التريوية، الإدارة التريوية،

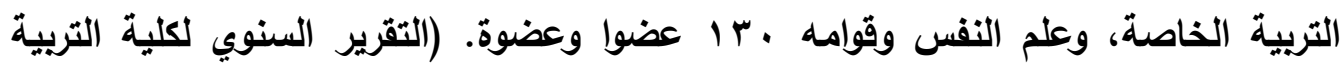

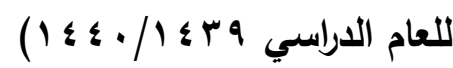

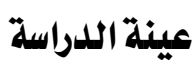

نظرا لصغر حجم المجتمع الأصلي للاراسة، اعتمدت الاراسة أسلوب الحصر الثامل لأعضاء هيئة التدريس الذكور والإناث من ذوي الرتبة العلمية أستاذ، أستاذ مشارك، وأستاذ

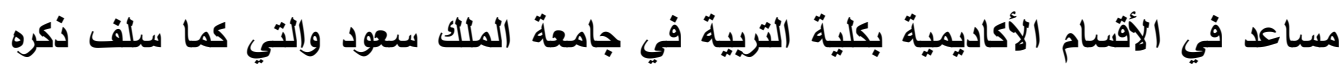

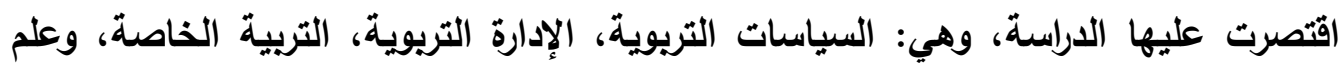

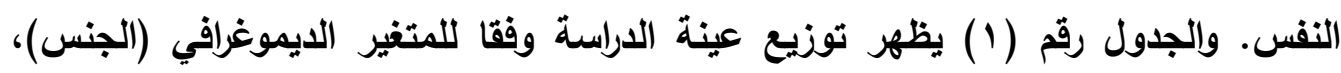
والجدول رقم (ץ) يظهر توزيع عينة الداسة وفقا للمتغير الايموغرافي (الرتبة العلمية). 


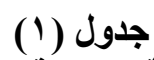

توزيع عينة الدراسة وفق الجنس

\begin{tabular}{|c|c|c|}
\hline النسبة & العدد & الجنس \\
\hline$\% 31,5$ & \&1 & ذكر \\
\hline$\% 68,5$ & $\wedge q$ & أنثى \\
\hline$\% 100$ & $1 \pi$. & المجموع \\
\hline
\end{tabular}

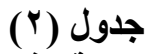

توزيع عينة الدراسة وفق الرتبة العبة العية

\begin{tabular}{|c|c|c|}
\hline النسبة & العدد & الرتبة العلمية \\
\hline 32,3 & $\varepsilon Y$ & أستاذ \\
\hline 30,8 & $\varepsilon$. & أستاذ مشارك \\
\hline 36.9 & $\leqslant 1$ & أستاذ مساعد \\
\hline $1 \cdots \cdots$ & 1T. & المجموع \\
\hline
\end{tabular}

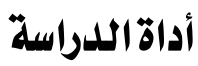

لتحقيق غرض الاراسة، تم تصميم استبانة مكونة من محور واحد، كالتالي:

1 ـ إعداد استبانة أولية صممت للإجابة على سؤال البحث، وذلك بالرجوع إلى الأدب التريوي والدراسات السابقة في مجال الداسة، وكذلك بالاطلاع على الأدوات المتعلقة بذلكت. وفي ضوء ذلك أعدت استبانة لمحددات تطبيق البحث النوعي في المجال التربوي، وتكونت من الآنات

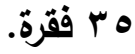

r. التحقق من صدق الأداة باستخدام دليلين: أولهما: من خلال عرضها على • · محكمين

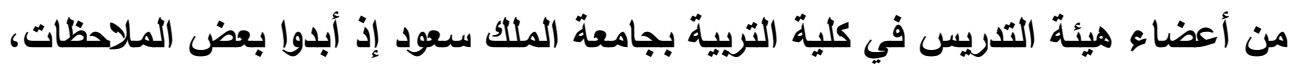

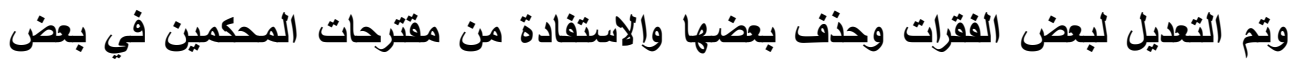
الفقرات. وثثانيهما: التحقق من الصدق باستخذام الاتساق الداخلي، وذلك بتطبيقها على

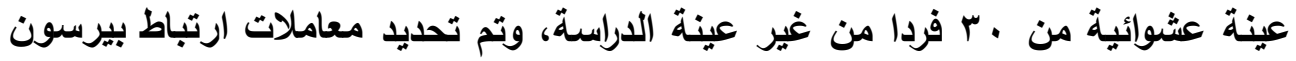

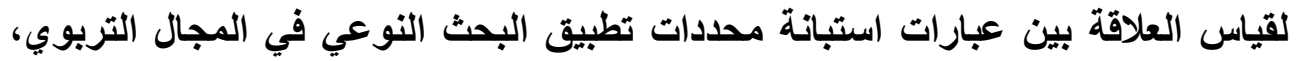
بالدرجة الكلية للاستبانة ، وتم والجدول رقم (ז) يوضح ذلك. Spss) استخدام ( 


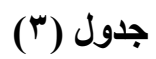

\section{معاملات ارتباط عبارات استبانة معوقات تطبيق}

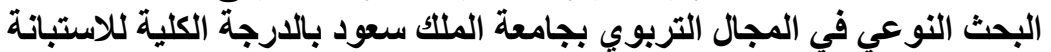

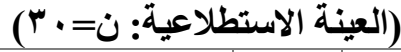

\begin{tabular}{|c|c|c|c|c|c|}
\hline معامل الارتباط & م & معامل الارتباط & r & معامل الارتباط & م \\
\hline$* * . \wedge \vee \vee 1$ & Y & . rmqo & 11 & $* *, . \Lambda \mu, \Lambda$ & 1 \\
\hline$* * . .9 r, r$ & Yr & $* * . \wedge 9 \%$ & Ir & $* * . \wedge \circ \vee q$ & $r$ \\
\hline$* * . . Y Y Y V$ & $r r$ & $* * . . \wedge \bullet Y r$ & $1 \%$ & $* * . . \wedge \vee \wedge \varepsilon$ & $r$ \\
\hline$* * .01 \mu r$ & $r \varepsilon$ & $* . \leqslant 11 \wedge$ & $1 \varepsilon$ & $* * \ldots \leqslant \wedge 0$. & $\varepsilon$ \\
\hline$* *, . \leq q \leq Y$ & Yo & $\cdot r \leqslant \leq q$ & 10 & .190. & 0 \\
\hline$* * . .0 \vee 1 \mu$ & YY & $* *$ *. I HOr & 17 & $* * . \wedge 17 V$ & 7 \\
\hline$* * . .09 \mu 1$ & YV & $* * . . \neg \bullet \mu V$ & $1 \mathrm{~V}$ & $* * . \Delta \mu l 0$ & $V$ \\
\hline$* * . .0 \vee 1 T$ & rA & $* . .211 \wedge$ & 11 & $* * . . \leqslant \wedge 0$. & $\Lambda$ \\
\hline$* * . . \nearrow \leq \wedge \neg$ & rq & $* * . .0 \leq \ldots$ & 19 & $* . . \varepsilon \mu V \mu$ & 9 \\
\hline$* * . .0 \vee 1 \mu$ & r. & $* . . \varepsilon \mu, \tau$ & r. & $* . \varepsilon r V \mu$ & 1. \\
\hline
\end{tabular}

* دالة إحصائيا عند مستوى ه •.

يتبين من الجدول (r) أن جميع معاملات ارتباط العبارات بالدرجة الكلية للاستبانة موجبة الهابة

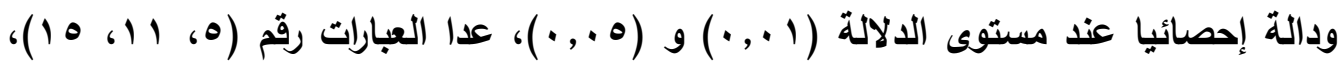
فقد كانت غير دالة إحصائيا. ونظرا لموافقة جميع المحكمين على أهمية هذه العبارات الثلاثة، لم تقم الباحثة بحذفها. r. التحقق من ثبات الأدة، إذ تم حساب ثبات الاستبانة بالتطبيق على عينة استطلاعية مكونة من ·r عضو هيئة تدريس من المتخصصين بالمجال التربوي بجامعة الملك سعود، وذلك من خلال استخدام معامل ألفاكرونباخ لحساب الثبات، حيث بلغت قيمة معامل الثبات الكلي لمحور الاستبانة ؟9 ه ، وهي قيمة عالية تعزز الثقة بالأداة ومقبولة لأغراض الدراسة الحالية، وذلك كما يوضحه الجدول رقم (؛ ).

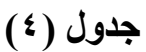
معاملات ثبات ألفا كرونباخ استبانة معوقات تطبيق البحث النوعي في المجال التربوي

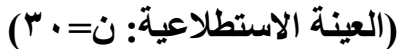

\begin{tabular}{|c|c|c|}
\hline معامل ثبات ألفا كرونباخ & العبارات & المحور \\
\hline$\because 9 \leq$ & $r$ & النوعي في المجال التربوي بجات معامعة الملتك \\
\hline
\end{tabular}


ع. تكونت أداة الدراسة بصورتها النهائية من · ب فقرة موزعة على محور واحد، وقد صيغت بدائل الإجابة على نمط مقياس ليكرت الخماسي لتقدير درجة الموافقة على النحو الآتي: كبيرة جدا، كبيرة، متوسطة، قليلة، قليلة جدا. ه. تم توزيع أداة الدراسة ورقيا، واسترداد جميع الاستبانات يدويا.

\section{عرض نتائج الدراسة وتحليلها وتقسيرها}

لتسهيل تفسير النتائج استخدمت الباحثة الأسلوب التالي لتحديد مستوى الإجابة على بنود الأداة. حيث تم إعطاء وزن للبدائل: (كبيرة جداً=ه، كبيرة=؛ ؛ متوسطة= بـ، قليلة= r، قليلة جداً= (1)، ثم تم تصنيف تلك الإجابات إلى خمسة مستويات متساوية المدى من خلال المعادلة التالية: طول الفئة = (أكبر قيمة- أقل قيمة) : عدد بائل الأداة = (0. . . . ، لنحصل على التصنيف التالي كما يبينه الجدول رقم (0). جدول (o)

توزيع للفئات وفق التّرج المستخدم في أداة البحث

\begin{tabular}{|c|c|}
\hline مدى المتوسطات & الوصف \\
\hline $0 . \cdots-\varepsilon . Y_{1}$ & كبيرة جداً \\
\hline$\left\{. r_{0}-r_{0} \leqslant 1\right.$ & كبيرة \\
\hline r.s. - r. & متوسطة \\
\hline r.T. - 1.11 & قليلة \\
\hline $1 . \wedge \cdot-1 .$. & قليلة جداً \\
\hline
\end{tabular}

عرض ثتائج اللدراسة وتحليلها

إجابة السؤال الأول: ما أهم المعوقات التي تحول دون تطبيق الباحثين من أعضاء هيئة التدريس بكلية التربية في جامعة الملك سعود للبحث النوعي في المجال التريوي وذلك من

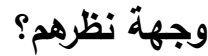

تمت الإجابة بحساب المتوسط الحسابي تنازليا، والجدول رقم (†) يوضح نتائج المتوسطات الحسابية والإنحرافات المعيارية لمتوسطات استجابة أفراد عينة الدراسة على

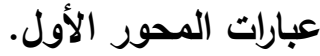




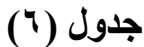

أهم المعوقات التي تحول دون تطبيق الباحثين من أعضاء هيئة التدريس بكلية التربية في جامعة الملك سعود للبحث النوانئ دئ في المجال التربوي

\begin{tabular}{|c|c|c|c|c|c|}
\hline الموافقة & الترتيب & الانحراف المعياري & المتوسط الحسبي & 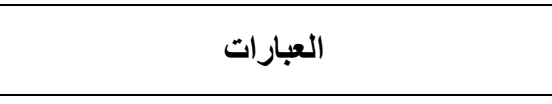 & م \\
\hline كبيرة جداً & 1 & $\cdot . r \Lambda$ & $\varepsilon .9 \mu$ & الخوف من عدم تحقى العلمية والموضوعية & 9 \\
\hline كبيرة جداً & r & $\because \mu r$ & $\varepsilon .9 r$ & 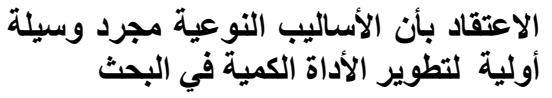 & $1 \leq$ \\
\hline كبيرة جداً & $r$ & $\cdot \because r$ & $\varepsilon .91$ & المتعارف والألفة لاستخدام أنماط البحث الكمي & 1 . \\
\hline كبيزة جداً & $\varepsilon$ & ו". & $\varepsilon . \wedge 9$ & 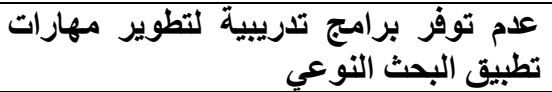 & r. \\
\hline كبيزة جداً & $\varepsilon$ & $\because \leqslant r$ & $\varepsilon . \wedge 9$ & أدوات البحث التوعية تدريبية على كيفية استخدام & 10 \\
\hline كبيرة جداً & 7 & 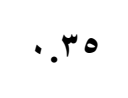 & $\varepsilon . \wedge \wedge$ & نلارة الخبراء والمدربين المتخصصين في & rq \\
\hline كبيرة جداً & v & $\because r q$ & $\varepsilon . \wedge 7$ & قالداخلي والخارجي لعينة البحث البط بين السلوك & $r \wedge$ \\
\hline كبيزة جداً & $\wedge$ & $\cdot . \mu$ & $\varepsilon . \wedge \bullet$ & 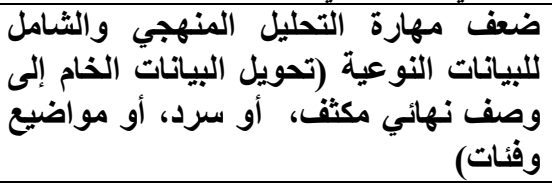 & $r \leqslant$ \\
\hline كبيرة جذاً & $\wedge$ & $\because \varepsilon \cdot$ & $\varepsilon . \wedge 0$ & 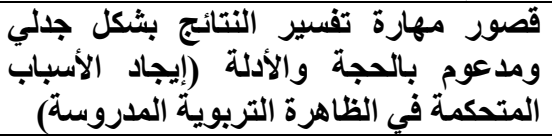 & 19 \\
\hline كبيرة جداً & 1. & $\cdot . \leqslant r$ & $\varepsilon . \wedge r$ & صعوبة اختيار المنهجية وتصميم البحث & $r r$ \\
\hline كبيزة جداً & 1. &. .74 & $\varepsilon . \wedge r$ & 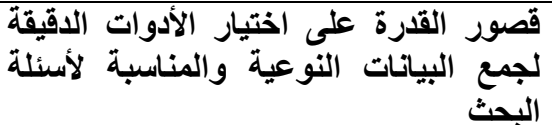 & 11 \\
\hline كبيرة جداً & Ir & $\because \leqslant \Lambda$ & $\varepsilon . \wedge 1$ & 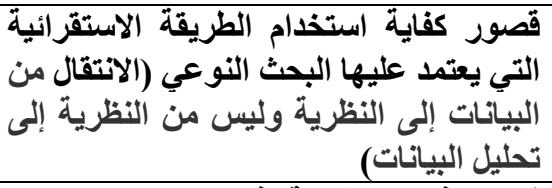 & $\varepsilon$ \\
\hline كبيزة جداً & ir & $\bullet \leqslant 7$ & $\varepsilon . \wedge$. & 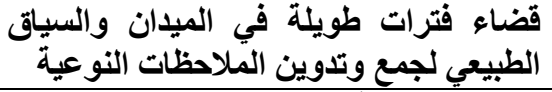 & ro \\
\hline كبيرة جداً & ir & 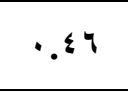 & $\leqslant . \wedge$. & طويل وجز اق عملية تحليل وتفسير البيانات وقت & rV \\
\hline كبيرة جداً & 14 & $.0 r$ & $\varepsilon . \wedge$. & ضفضامة كمية البيانات النوعية (معلومات & 0 \\
\hline
\end{tabular}




\begin{tabular}{|c|c|c|c|c|c|}
\hline كبيزة جداً & 17 & $\because \leqslant 9$ & $\varepsilon . \vee 9$ & تعميم ونقل النتائج على الحالات والسياقات & r. \\
\hline كبيرة جداً & iv & $.0 \leq$ & $\varepsilon . V V$ & تلذني مستوى الممارسة التدريجية في تطبيق & $\wedge$ \\
\hline كبيرة جداً & 11 & $\because 0$ & $\varepsilon . \vee 0$ & ضتقف تحقق الصرامة المنهجية في إعداد & rq \\
\hline كبيزة جداً & 19 & $\because 9 r$ & $\varepsilon .00$ & والذاتية في تفسيز التتائج الانتقائي للملاحظات & 11 \\
\hline متوسطة & r. & I.Vr & $r . \Lambda$ & استخدام أدوات جمع البيناتيات باحثين مدربين على & ir \\
\hline متوسطة & Yl & 1.7. & r.o & النوعية & 17 \\
\hline متوسطة & rr & 1.71 & Y.90 & التعاطف وتطوير علاقة مع المشاركين & iv \\
\hline متوسطة & $r r$ & 1.04 & r.Vr & كثيرا من الوقة بين الباحث والمشاركين يستغرق & ir \\
\hline متوسطة & $r \leq$ & 1.07 & ५. ४ & قالنوعي المراجع المترجمة حول مناهج البحث & 7 \\
\hline متوسطة & ro & 1.00 & Y.TE & صعوبة توافر معايير الصدق & $r$ \\
\hline متوسطة & Y & $1.0 r$ & r. & انخفاض درجة الثقة في البيانات & V \\
\hline متوسطة & $r V$ & $1.0 Y$ & Y.71 & غموض معايير تحليل البيانات النوعية & rr \\
\hline قليلة & $r \wedge$ & $1 . \varepsilon \varepsilon$ & r.or & والثقافية والالتزام بالقواعد والمبادئ الأخلاقية & YI \\
\hline قليلة & rq & هr. & Y. $\leqslant 1$ & 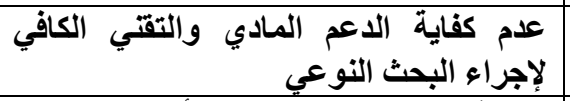 & r \\
\hline قليلة & r. & I.rr & ૫. & 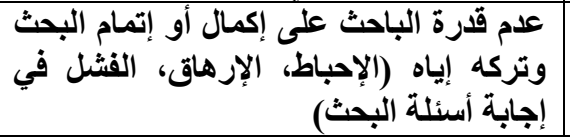 & 1 \\
\hline كبيرة & & $.0 V$ & $\varepsilon .0$ & \multicolumn{2}{|c|}{ المتوسط* العام } \\
\hline
\end{tabular}

* المتوسط الحسابي من • درجات

يتضح من الجدول (†) موافقة العينة بلرجة كبيرة حول عبارات محور المعوقات دات

التي تحول دون تطبيق عينة الدراسة للمنهج النوعي في المجال التربوي، فقد بلغ المتوسط الحسابي ه ...؛ ـ كما يوضح الجدول أن 9 أعائق من العوائق الثلاثين حصل على موافقة عينة الدراسة بدرجة كبيرة جدا ، وقد حصلت كل من العبارات (الخوف من عدم تحقق العلمية

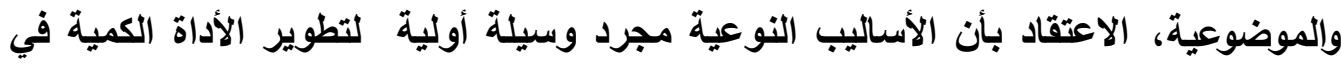
البحث، الميل والألفة لاستخدام أنماط البحث الكمي المتعارف عليها) على المراتب الثلاثة

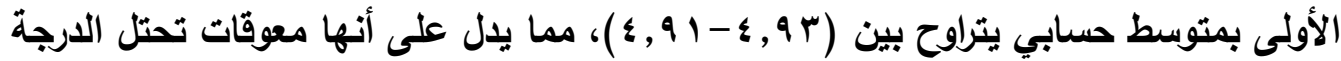

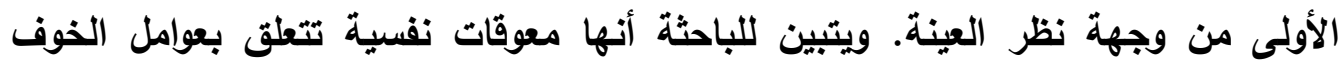


والرهبة من تطبيق البحوث النوعية لاعتقاد أفراد العينة بأنها غير قادرة على التحكم في أبعاد الدراسة في كافة الأوقات، أيضا عدم الثقة بها كتصميم ومنهج بحثي أساسي ذو جدوى كيفية وأهمية نوعية، بالإضافة إلى ما توفره التصاميم الكمية من شعور بالراحة، لاعتياد أصحابها من الباحثين على تطبيقها في بحوثهم التربوية، إلى جانب أن البحوث النوعية تقع خارج منظقة الراحة والاعتياد منهم، لأنها أساليب بحثية جديدة غير مألوفة لايهم. وتتفق النتيجة/

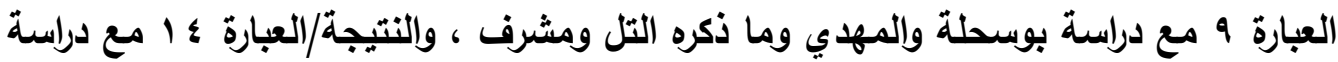
القحطاني، والنتيجة/العبارة ـ 1 مع دراسة العزاوي والزايدي.

وحصلت كل من العبارات الثلاث وهي معوقات تدريبية كما تصنفها الباحثة وهي

(عدم توفر برامج تدريبية لتطوير مهارات تطبيق البحث النوعي، عدم توفر أدلة تدريبية على كيفية استخدام أدوات البحث النوعي، وندرة الخبراء والمدربين المتخصصين في البحث

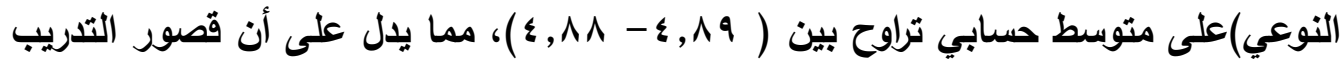
في المناهج النوعية يعد بلرجة كبيرة جدا معوقا يحد من ممارسة وتطبيق عينة الدراسة للبحوث النوعية في المجال التريوي؛ وتتفق النتيجة/العبارة ، ب و هـ هـ مع دراسة الزايدي، واتفقت النتيجة/العبارة צr مع دراسة كل من الموسى والزايدي وياتثيرجي. أما المعوقات المهارية كما تراها الباحثة وهي (قصور القدرة على الربط بين السلوكي الاخلي والخارجي لعينة البحث ، ضعف مهارة التحليل المنهجي والثامل للبيانات النوعية (تحويل البيانات الخام إلى وصف نهائي مكثف، أو سرد، أو مواضيع وفئات) ، قصور مهارة تفسير النتائج بشكل جللي ومدعوم بالحجة والأدلة (إيجاد الأسباب المتحكمة في الظاهرة التريوية المدروسة ، صعوية اختيار المنهجية وتصميم البحث المناسب لأهداف البحث ، قصور القدرة على اختيار الأدوات الدقيقة لجمع البيانات النوعية والمناسبة لأسئلة البحث، قصور كفاية استخدام الطريقة الاستقرائية التي يعتمد عليها البحث النوعي (الانتقال من البيانات إلى النظرية وليس من النظرية إلى تحليل البيانات) فقد حصلت على متوسط

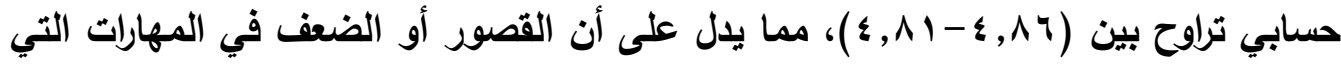
يتطلبها البحث النوعي يعد بدرجة كبيرة جدا عائقا لاى أفراد عينة يحول دون تطبيقهم للبحث

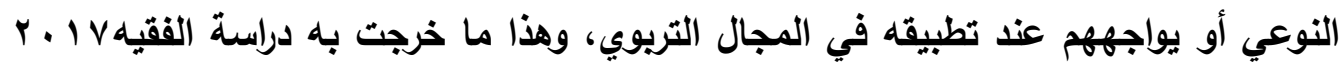

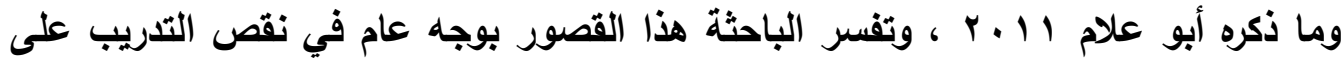


هذا النوع من التصاميم البحثية التي تتطلب مهارات عالية وإمكانات قد لا تتوافر لاى كثير

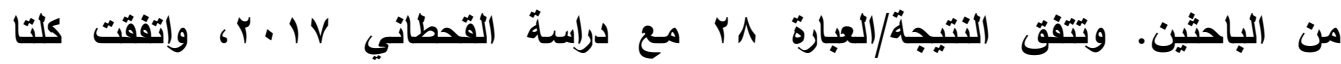

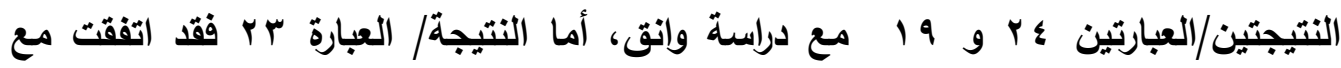

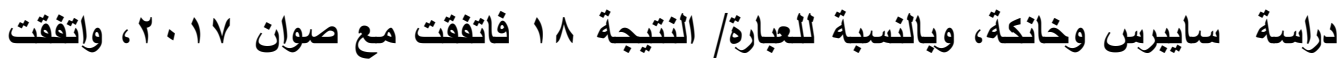

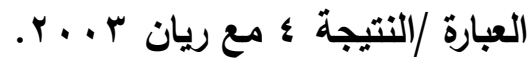

وقد حصلت المعوقات الميدانية كما تصنفها الباحثة، والتي تمثلها كل من العبارة

ه r (قضاء فترات طويلة في الميذان والسياق الطبيعي لجمع وتدوين الملاحظات النوعية) ، والعبارة rV (استغراق عملية تحليل وتفسير البيانات وقت طويل وجه كبير) ، والعبارة ه (ضخامة كمية البيانات النوعية) على الترتيب الثالث عثر بناء على قيمة المتوسط الحسابي لها وقدره 4,80، مما يدل على أن جمع كم هائل من البيانات حول الظاهرة وتدوينها يتطلب وجود الباحث في الميدان أو الحقل الطبيعي التربوي لفترات طويلة، ويستلزم جها وطاقة ذهنية كبيرة، وجسدية كذلك لتحليلها وتفسيرها ، وهي في نظر عينة الدراسة بمثابة معوقات تحد بدرجة كبيرة جدا من تطبيقهم للبحث النوعي في المجال التربوي، أو أثناء تطبيقهم له.

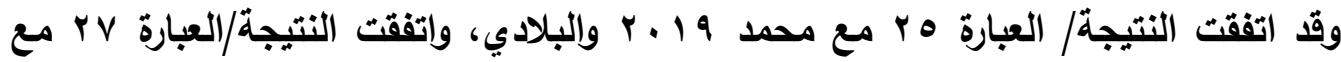
أبو علام r 1 ـ r، ودراسة وانق، ودراسة جورس وفاريا وأمليدا، كما واتفقت النتيجة/ العبارة ه مع أبو علام I 1 ـ r، ودراسة إلكسندروس وسايبرس. أما العبارات الثلاث: (عدم الالتزام بالقواعد والمبادئ الأخلاقية والثقافية والقانونية:

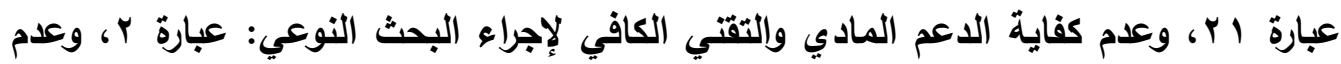
قرة الباحث على إكمال أو إتمام البحث وتركه إياه: عبارة 1) فقد حصلت على متوسط إنى حسابي يتراوح بين (2,52 - 2,38) وموافقة قليلة من عينة الدراسة، مما يدل على أن أعضاء هيئة التدريس الباحثين على وعي ذاتي بمختلف الاعتبارات الأخلاقية والثقافية والقانونية، ويحصلون على الدعم المادي والتقني الكافي، ومن النادر تركهم إتمام أبحاثهم

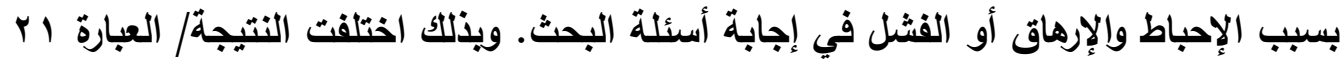

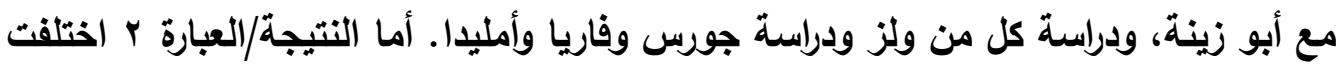

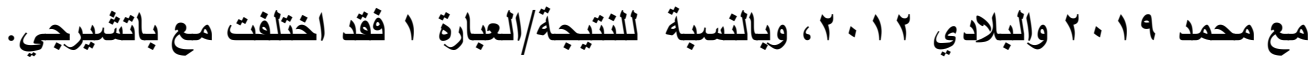


إجابة السوأل الثاني: هل هناك فروق ذات دلالة إحصائية بين استجابات أفراد العينة

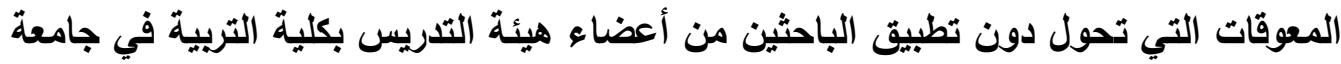

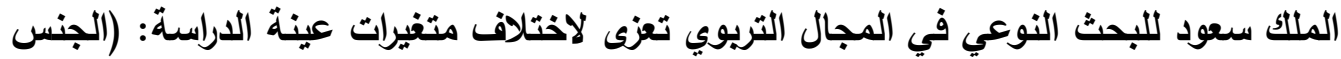

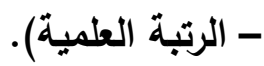

للإجابة على هذا السؤال قامت الباحثة باستخذام اختبار (ت) لالالة الفروق بين مجموعتين مستقلتين للتعرف على الفروق في استجابات أفراد العينة حول المحددات التي تحول دون تطبيق الباحثين من أعضاء هيئة التّريس بكلية التربية في جامعة الملك سعود للبحث النوعي في المجال التربوي تبعاً لاختلاف متغير الدارسة:

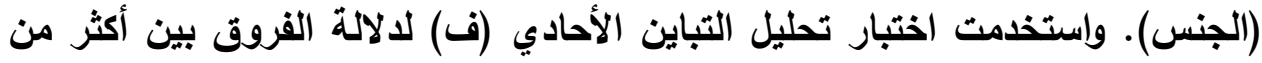
مجموعتين مستقلتين للتعرف على الفروق تبعاً لاختلاف متغير الدارسة: (الرتبة الآنان العلمية). والجدولين التاليين (V) و(^) يبينان النتائج التي تم التوصل إليها:

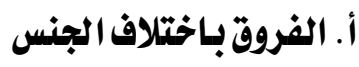

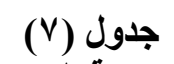

اختبار (ت) لالالة الفروق في استجابات عينة الدراسة حول المعوقات التي تحول دون تطبيق

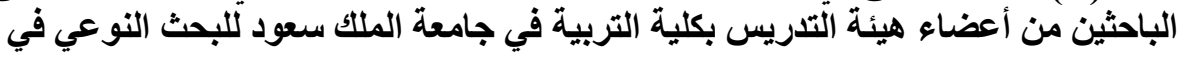

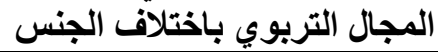

\begin{tabular}{|c|c|c|c|c|c|c|}
\hline التعليق & مستوي & قيمة ت & المعياري & الحستابي & العدد & نوع العينة \\
\hline \multirow{2}{*}{ دالة عند مستوى } & \multirow{2}{*}{$\because \cdots$} & \multirow{2}{*}{$r . \leqslant r$} & $\because \leqslant 0$ & \&.rq & $\leqslant 1$ & ذكر \\
\hline & & &. .09 & r.qT & 19 & أنثى \\
\hline
\end{tabular}

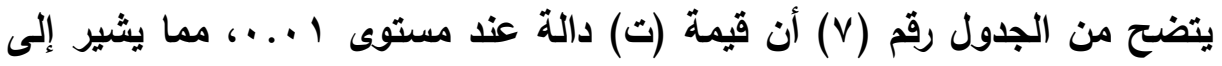
وجود فروق ذات دلالة إحصائية بين استجابات عينة الدراسة حول المعوقات التي تحول التهول

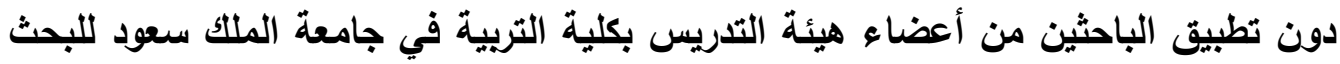
النوعي في المجال التربوي، تعود لاختلاف جنس العينة، وكانت تلك الفروق لصالح عينة الذكور، أي أن أعضاء هيئة التدريس الذكور يرون أن المعوقات في تطبيق البحث النوعي

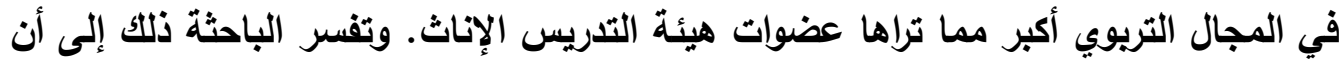
أعضاء هيئة التريس الذكور أكثر اهتماما بتطبيق البحوث النوعية، وأكثر إدراكا للمعوقات 
التي واجهته أثناء تطبيق البحوث النوعية في الميدان التريوي. وتتفق هذه النتيجة مع النتيجة المماثلة التي خرجت بها دراسة الزايدي.

ب. الفروق باختلاف اللدرجة العلمية

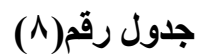

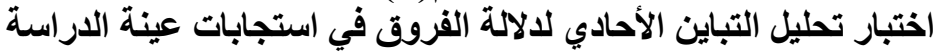

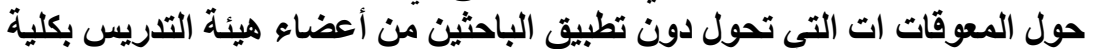

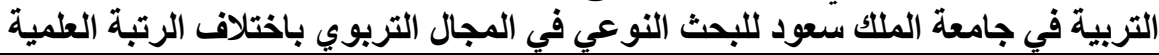

\begin{tabular}{|c|c|c|c|c|c|c|}
\hline التعليق & الدلالة & قيمة ف & متوسطات & الحرية & المربعات & مصدر التباين \\
\hline \multirow{2}{*}{ مستوى 1 •.. } & \multirow{2}{*}{$\because \cdots$} & \multirow{2}{*}{$r q 0.99$} & $1 V . \leqslant 0$ & r & $r \varepsilon . \wedge q$ & بين المجموعات \\
\hline & & & $\because \cdot 7$ & IrV & $v . \leqslant q$ & داخل المجموعات \\
\hline
\end{tabular}

يتضح من الجدول رقم (^) أن قيمة (ف) دالة عند مستوى ا +...، مما يشير إلى

وجود فروق ذات دلالة إحصائية بين استجابات عينة الدراسة حول المعوقات التي تحول دون تطبيق الباحثين من أعضاء هيئة التدريس بكلية التربية في جامعة الملك سعود للبحث النوعي في المجال التريوي في تلكك الأبعاد، تعود لاختلاف الرتبة العلمية لأفراد العينة. والجدول رقم (9) يكشف عن مصدر تلك الفروق باستخدام اختبار شيفيه.

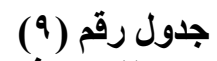

اختبار شيفيه لتوضيح مصدر الفروق في استجابات عينة الدار استة

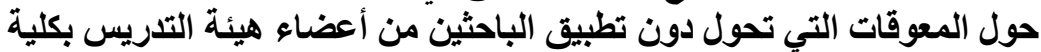

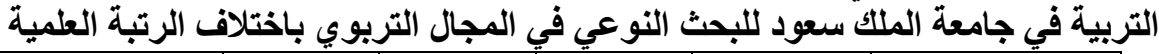

\begin{tabular}{|c|c|c|c|c|c|}
\hline الفرق لصالح & مستاعد & مشارك & أستاذ & الحسابي & الرتبة العلمية \\
\hline & $1 . Y T-$ &..$\leqslant 9$ & -- & r. $\leqslant \varepsilon$ & أستاذ \\
\hline أستاذ مشارك & $\cdot V \leqslant-$ & -- & $* . . \leqslant 9$ & $r .94$ & أستاذ مشارك \\
\hline أستاذ مساعد & -- & $* . . V \leq$ & $* 1 . Y \mu$ & $\varepsilon .7 V$ & أستاذ مساعد \\
\hline
\end{tabular}

$$
\text { * تعني وجود فروق دالة عند مستوى } 0 \text { •. }
$$

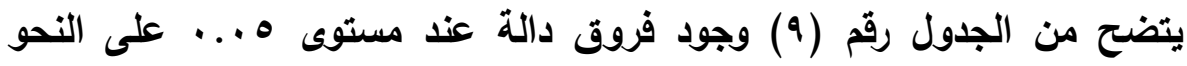

1 - توجد فروق دالة في استجابات أفراد العينة بدرجة (أستاذ)، وبين استجابات أفراد العينة بلرجة (أستاذ مشارك)، وذلك لصالح استجابات أفراد العينة بدرجة (أستاذ مشارك)، أي أن 
أعضاء هيئة التدريس برتبة (أستاذ المشارك) يرون أن معوقات تطبيق البحث النوعي في المجال التريوي أكبر مما يراها أعضاء هيئة التدريس برتبة (أستاذ). r- توجد فروق دالة في استجابات أفراد العينة بدرجة (أستاذ، أستاذ مشارك)، ويين استجابات أفراد العينة بلرجة (أستاذ مساعد)، وذلك لصالح استجابات أفراد العينة بلرجة (أستاذ مساعد)، أي أن أعضاء هيئة التدريس برتبة (أستاذ مساعد) يرون أن معوقات في تطبيق البحث النوعي في المجال التريوي أكبر مما يراها أعضاء هيئة التدريس برتبة (أستاذ، أستاذ مشارك).

ويعود سبب هذه النتيجة إلى مستوى الخبرة المرتبط بالارجة العلمية، التي تقل معها المعوقات التي تواجه الباحثين من أعضاء هيئة التدريس بكلية التربية من درجة أستاذ دكتور ثم أستاذ مشارك عند تطبيقه للبحث النوعي في المجال التريوي قياسا بالباحثين التريويين أعضاء هيئة التدريس على درجة أستاذ مساعد، واختلفت هذه النتيجة مع ما جاءت به لنتائج دراسة الزايدي التي كشفت عن وعدم وجود فروق ذات دلالة إحصائية عند مستوى (ه, •) بين متوسطات استجابات أفراد عينة الدراسة تبعا لمتغير الرتبة العلمية.

التوصيات والمترتحات

أولا: توصيات اللدراسة

خلصت الاراسة إلى عدة نتائج تكثف عن أهم معوقات تطبيق البحث النوعي في المجال التريوي، وتمثلت في أريعة معوقات وافقت عليها بدرجة كبيرة جدا عينة الدراسة من الباحثين والباحثات أعضاء وعضوات هيئة التدريس بكلية التربية في جامعة الملك سعود بكل من الأقسام (السياسات التربوية، الإدارة التربوية، التربية الخاصة، وعلم النفس)، وكانت بحسب تصنيف الباحثة معوقات نفسية، معوقات تدريبية، معوقات مهارية، ومعوقات ميدانية،

وعليه توصي الدراسة بالآتي:

1 ـ كسر حاجز الهيبة والرهبة والتخوف والتهرب من ممارسة وتطبيق البحث النوعي ، بنشر ثقافة الاعتياد الضروري لممارسة هذا النوع من البحوث الكيفية الميدانية، وتثجيع الباحثين من أعضاء هيئة التدريس على استخدام المنهج النوعي من خلال الإشادة بالأبحاث النوعية على مستوى القسم والكلية والجامعة، لتصبح منهجا علميا يُعتمد في التي الأبحاث العلمية المستقبلية. 
r. تكثيف التدريب على البحوث النوعية الميدانية، وخاصة في الجانب التطبيقي لعملية

$$
\text { تصنيف البيانات النوعية وترميزها وتفسيرها. }
$$

r. تنمية الدهارات الأساسية والضرورية التي تعتمدها البحوث النوعية بالمشاركة البحثية

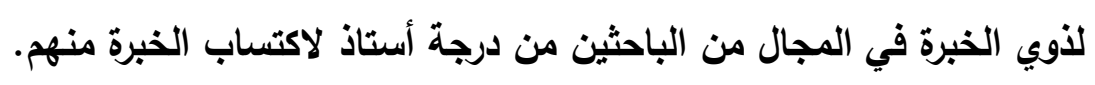

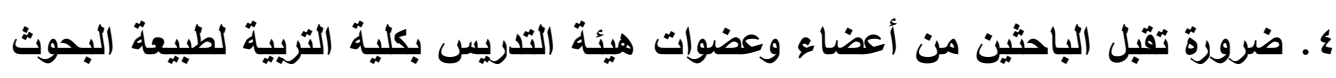

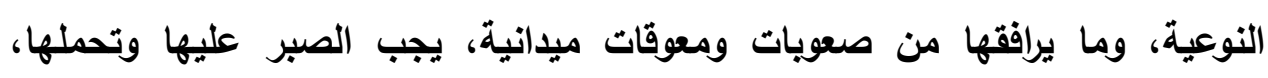

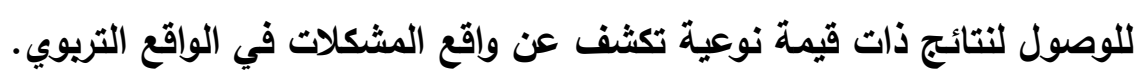

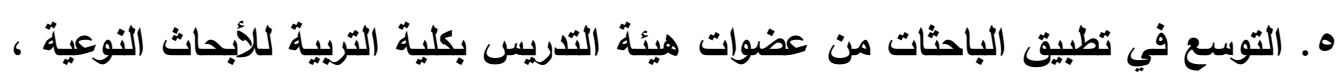
للمساهمة بها في حل المشكلات في الحقل والميدان التريوي. ثانيا : مقتز حات الدراسة

تقترح الدراسة الحالية إجراء الدراسات المستقبلية الآتية:

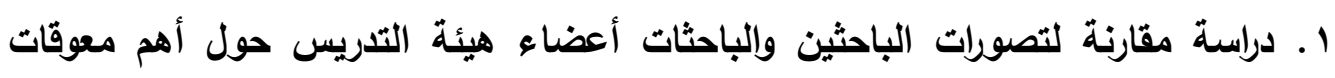

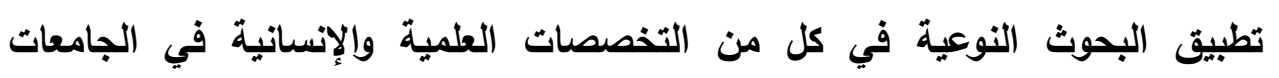

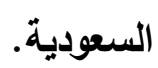

r r دراسة مقارنة لمعوقات تطبيق البحوث النوعية في المجالات العلمية والإنسانية بين ثلاثة

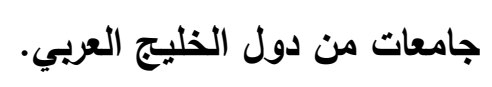

r. دراسة مقارنة لمعوقات تطبيق البحوث النوعية في المجال التريوي بين ثلاثة جامعات

$$
\text { عربية. }
$$

؛. دراسة مقارنة لمعوقات تطبيق البحوث النوعية في المجال التربوي بين مجموعة من

$$
\text { الجامعات العربية، وأخرى أجنبية. }
$$




\section{المراجع}

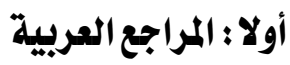

الآغا، إحسان والأستاذ، محمود (ץ . . ץ). مقدمة في تصعيم البحث التربوي (طץ)، عزة -

فلسطين: مطبعة الرنتيسي للطباعة والنشر .

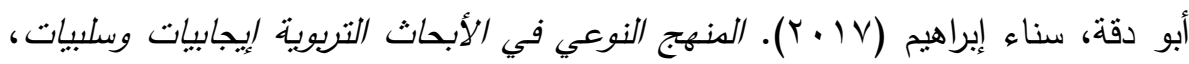

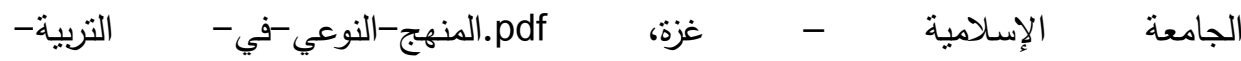

http://site.iugaza.edu.ps/sdagga/files/

أبو زينة، فريد كامل؛ الإبراهيم، مروان؛ قنديلجي، عامر؛ عدس، عبد الرحمن؛ عليان، خليل

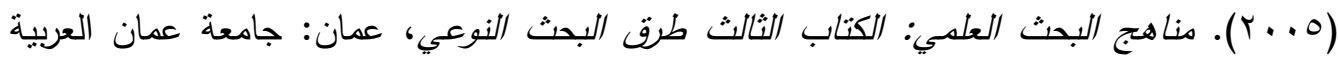

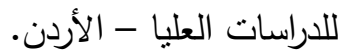

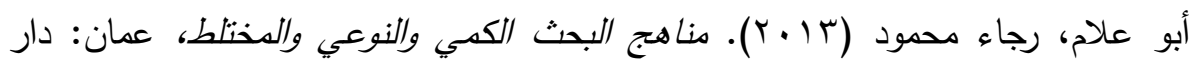

المسيرة للنشر والتوزيع.

أبو علام، رجاء محمود (1) (Y). مناهج البحث في العلوم النفسية والتربوية (طV)، القاهرة:

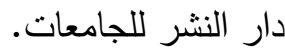

بو سحلة، والمهدي، بن عيسى محمد (7 ( • (Y). الدراسات السوسيولوجية في الجزائر بين

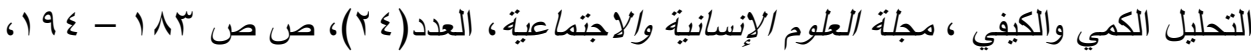
https://dspace.univ-

ouargla.dz/jspui/bitstream/123456789/10586/1/S2416.pdf

البلادي، عبد الرحمن (10 • ب). مقدمة في البحث النوعي، دورات المكتبة الرقمية السعودية

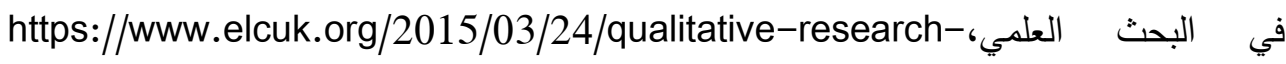
course/

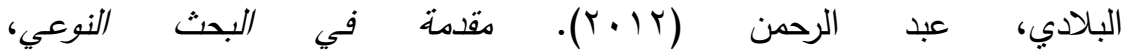

http://educad.me/1364/qualitative-research/

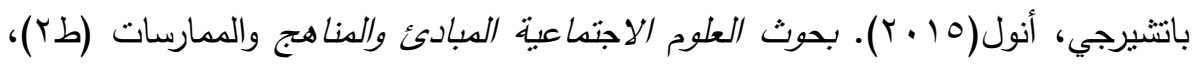

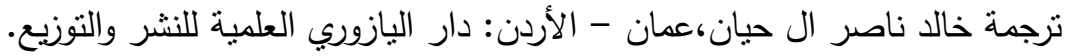

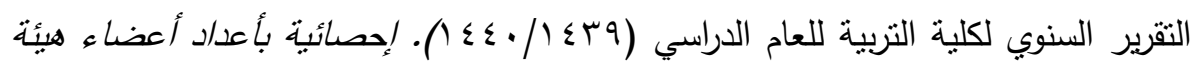

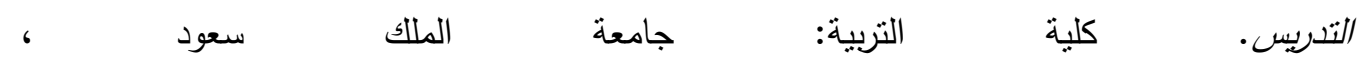


https://education.ksu.edu.sa/sites/education.ksu.edu.sa/files/attach/tqryr_kly_ Itrby_40.pdf

التل، سعيد وآخرون (0. . r). طرق البحث النوعية، الأردن: جامعة عمان العربية للاراسات

الجلاد، ماجد زكي (11) (1). البحث العلمي في التربية في الأردن: دراسة تحلبلية بيلبيورافية، المعهد العالي للفكر الإسلامي - هرندن - فرجينيا، الولايات المتحدة المريكية، دار ورد

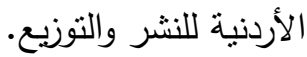

حسنين، زغلول عباس (1. (Y). المعوقات التي تواجه مشرفي التدريب الميداني عند

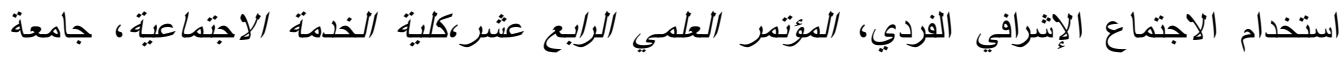
حلوان.

حسنين، شوقي السيد ( . . †). معجم مصطلحات العلوم التربوية، الرياض: مكتبة العبيكان.

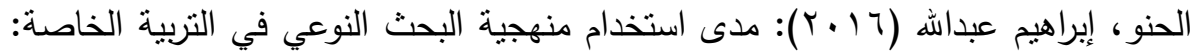

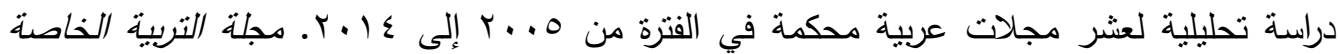

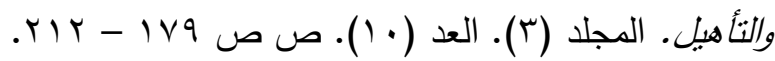

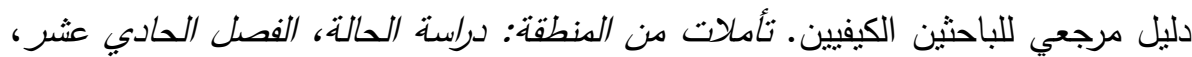

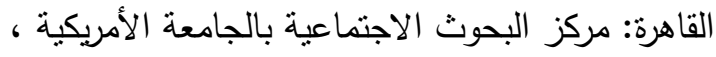
www1.auceypt.edu/academic/qualitative researchs/pdf/qualitativeResearch-chapter11.pdf.

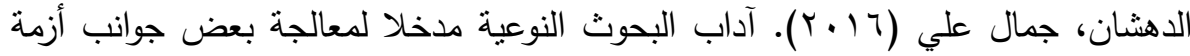

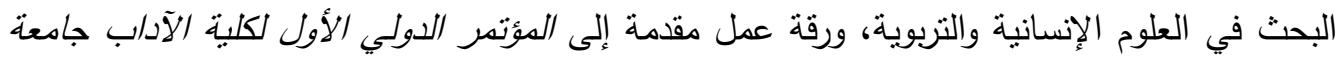

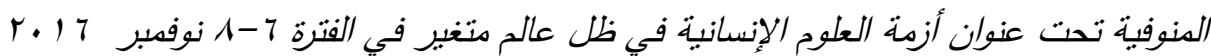

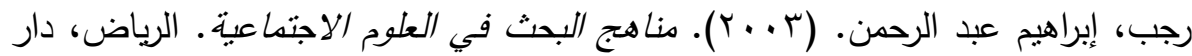

عالم الكتب للطباعة والنشر والتوزيع.

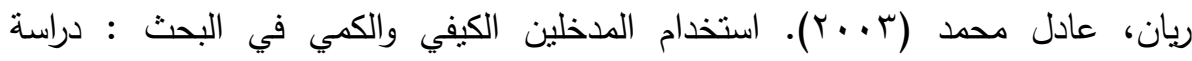

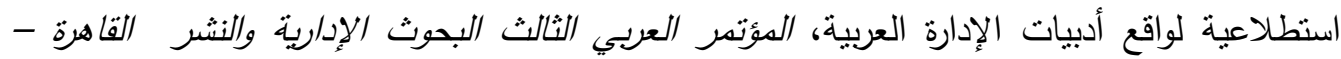

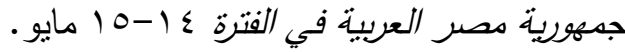

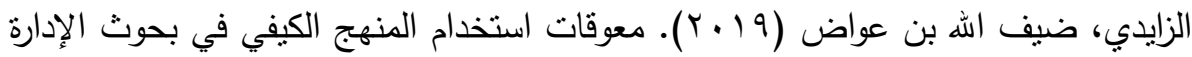

والقيادة التربوية من وجهة نظر أعضاء هيئة التدريس بالجامعات السعودية. المجلة الدولية لتربوية

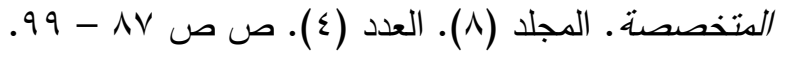




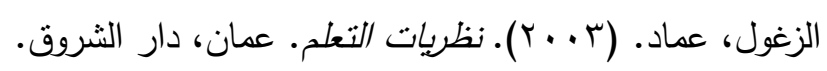

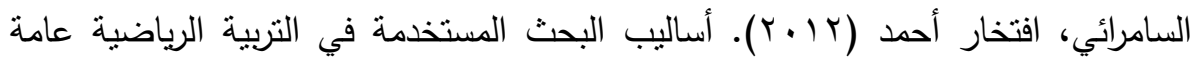

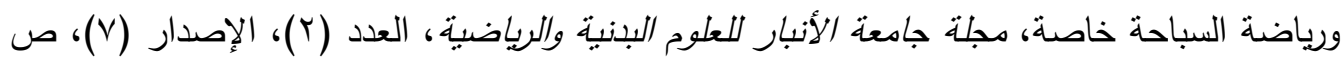
. r) -

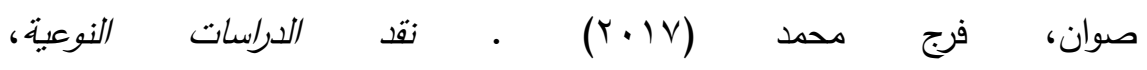

(academiworld.org/criticising- qualitative - research/

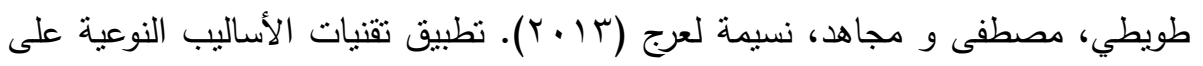

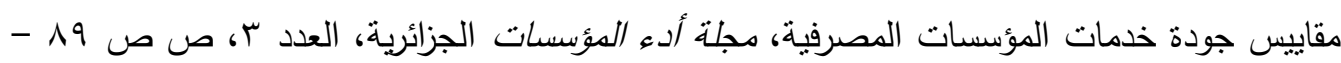

عبيدات، محمد ( (... ب). بحوث التسويق: الأسس، المرحل والتطبيقات، دار وائل للنشر والتوزيع: عمان، الأردن. - مان.

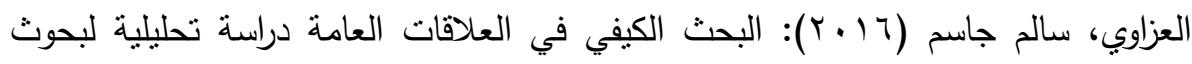

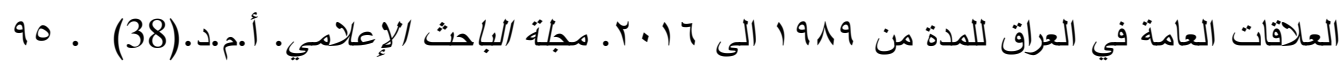
$11 \leq-$

الفضل، مؤيد (1 + . ץ). الأساليب الكمبة والنوعية في دعم قرارات الدنظمة، عمان: دار الوراق للنشر والتوزيع: الأردن.

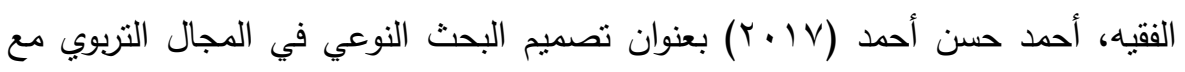

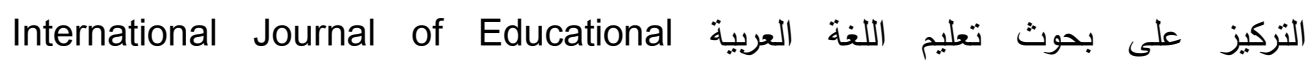
Psychological Studies - Vol. 2, No. 3, pp. $354-368$

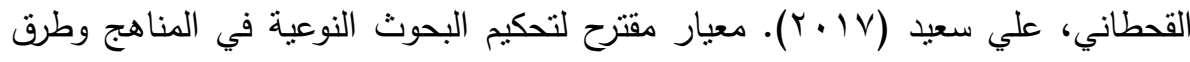

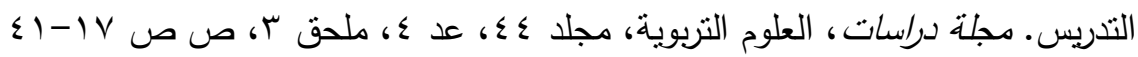

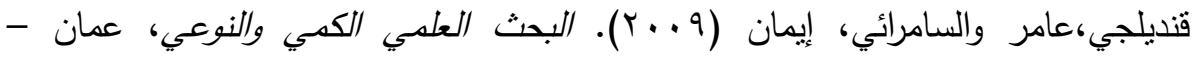
الأردن: https://hsracademy.com/product/\%D9\%83\%D8\%AA\%D8\%A7\%D8\%A8\%D8\%A7\%D9\%84\%D8\%A8\%D8\%AD\%D8\%AB\%D8\%A7\%D9\%84\%D8\%B9\%D9\%84\%D9\%85\%D9\%8A\%D8\%A7\%D9\%84\%D9\%83\%D9\%85\%D9\%8A\%D9\%88\%D8\%A7\%D9\%84\%D9\%86\%D9\%88\%D8\%B9\%D9\%8A/ 
مشرف، شيرين عيد (T ( ا r) روية بحثية تجديديةلالستخدام البحث النوعي في معالجة

بعض جوانب أزمة البحث التربوي. مجلة المعرفة التربوبية. الجمعية المصرية لأصول التربية. ع). $. \vee \cdot-1$

محمد،أحمد علي الحاج (9 ( • ( ). البحوث النوعية (الكبفية)، سلسلة إصدارات مركز جزيرة العرب للبحوث والتقييم.

محمد، عبد الفتاح (r99 (1)). مدارسة طربقة تنظبم المجتمع لمواجهة معوقات المشاركة، جامعة القاهرة، كلية الخدمة الاجتماعية بالفيوم، رسالة دكتوراه غير منشورة. منصور ، علي. ( ( . . r). التعلم ونظرباته . اللاذقية، منشورات جامعة تشرين، مديرية الكتب والمطبوعات.

الموسى، أسماء إبراهيم (9 ( • (Y).تصور مقترح لتفعبل البحث الكبفي في تخصص أصول التربية بالجامعات السعودية في ضوء الخبرات العالمبة الدعاصرة، رسالة دكتوراه غير منشورة، كلية العلوم الاجتماعية: قسم أصول التربية، الرياض: جامعة الإمام محمد بن سعود الإسلامية. الهلالات، خليل إبراهيم (1 ( • (Y). معوقات العمل التطوعي في الأردن، المجلة الأردنبية 6) العدد 6) المجلد الاجتماعبة https://journals.ju.edu.j/JJSS/article/view/101696/8718

\section{ثانيا : المراجع الأجنبية}

Abedini, Samireh; Imani, Elham; Fazli, Abbas (2019): Educational Ethical Challenges in the Viewpoint of Students in Medical Sciences: AQualitative Study with Content Analysis Approach, Hormozgan Medical Journal: 23 (2); e89932, OI: 10.5812/hmj.89932.

Alexandros, Kapoulas; Miljana, Mitic; Kaufmann, Hans Ruediger (2012): Understanding challenges of qualitative research: rhetorical issues and reality traps, Qualitative Market Research: An International Journal, VL. 15, p.p 354-368.

Amirav, Dorit Redlich (2014). New Emerging Technologies in Qualitative Research. The Qualitative Report 2014, Vol 19, How to Article 12, 1-14, http: www.nova.edu/ssss/QR/QR19/redlich-amirav12.pdf.

Anderson, Claire. (2010) Presenting and Evaluating Qualitative Research, American Journal of Pharmaceutical Education, 141(8)74.

Ary, Christine K. Sorensen Donald; Jacobs, Lucy Cheser; Razavieh, Asghar (2010). Introduction to research in education (8th ed.): Cengage Learning. 
Barbour, R. (2008). Entroducing Qualitative Research: Astudent Guide to the craft of Doing Qualitative Research. London: Sage.

Creswell, J. W. (2005). Educational research: Planning, conducting, and evaluating quantitative and qualitative research. Upper Saddle River, New Jersey: Pearson Education, Inc.

Creswell, J. W. (2007). Qualitative inquiry and research design: Choosing among five approaches, (2nd Ed.) London: SAGE Publications.

Creswell, J.W. (1998). Qualitative Inquiry and research desigh: choosing among five traditions. London: Sage.

Crotty, m. (1998). The Foundations of Social Research: Meaning and Perspective in the Research Process. London: Sage.

Cypress, Brigitte S (2019): Qualitative Research: Challenges and Dilemmas, Dimensions of Critical Care Nursing journal, Volume 38 - Issue 5 $\mathrm{p}$ 264-270, https://journals.lww.com/dccnjournal/Abstract/2019/09000/Qualitative_Resear ch_Challenges_and_Dilemmas.7.aspx

Denscombe, M. (2010) The Research Guide for Small- Scall Research Projects, 4th edithion, Maidenhead: Open University Press.

Denzin, Yvonna S Lincoln (Eds). (2000) Handbook of Qualitative Research, $2^{\text {nd }}$ edition. London, Thousand Oaks, Calif.

Dickson-Swift, Virginia; Games, Erica L; Kippen, Sandra (2007): Doing Sensitive Research: What Callenges do Qualitative Researches Face? Volume: 7 issue: 3 , page(s): https://doi.org/10.1177/1468794107078515.

Edwards, A. (2010) Qualitative designs and analysis, in $G$. MacNaughton, S. Rolfe and I. Siraj-Blatchford (eds) Doing Early chilldhood Research: International Perspectives on Theory and Practice, $2^{\text {nd }}$ edition. Maidenhead: Open University press.

Erickson, F. (1986). Qualitative methods in research on teaching. In M. Wittrock (Ed.), Handbook of research on teaching (3rd ed., pp. 119-161). New York: Macmillan.

Fine, M., Weis, L., Weseen, S. and Wong, L. (2000). For whom? Qualitative research, representations and social responsibilities, in N.K.

Gill. Peter, R.; Elizabeth, C. Temple, (2014). Walking the Fine line Between Fieldwork Success and failure: Advice for New Ethnographers, Journal of Research Practice, vol 10, Issue 1, Article M2, 1-13.

Guba, E. G., and Lincoln, Y. S. (1988). Do inquiry paradigms imply inquiry Methodologies? In D. M. Fetterman (ed.), Qualitative Approaches to Evaluation In Education: The Silent Scientific Revolution, pp. 89-115. New York: Praeger. 


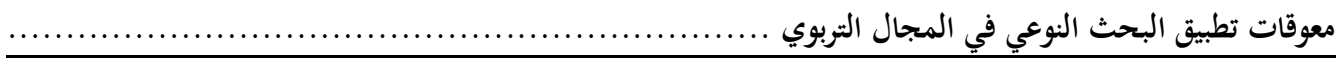

Hamidreza Khankeh, Maryam Ranjbar, Davoud KhorasaniZavareh, Ali Zargham-Boroujeni, and Eva Johansson(2015): Challenges in conducting qualitative research in health: A conceptual paper, Iran J Nurs Midwifery Res. 2015 Nov-Dec; 20(6): 635-641, doi: 10.4103/17359066.170010, PMCID: PMC4700679, PMID: 26793245.

Hilal, A., \& Alabri, S. (2013). Using NVIVD for Data analysis in qualitative research. International Interdiscplinary, Journal of Education, 2(2), 181-186, https://doi.org/10.1108/13522751211257051

Mottern, R. (2013)." Teacher-Student relationships in Court-Mandated Adult Education: A Phenomenological Study".The Qualitative Report (vol. 18, Article 13, 1-40).University of Tennessee, Knoxville, Tennessee: USA Publishers.

.Queiros, A; Faria, D \& Almeida, F (2017). Strengths and Limitations of Qualitative and Quantitative Research Methods. European Journal of Education Studies. 3 (9), 369- 387.

Ramadhan, H (2015). The challenges of qualitative research: Can it be used to strengthen decision making for health care in Uganda? Medical Practice and Review. 6 (3), 24-30.

Robert k. Yin. (2011). Qualitative Research from Start to Finish, Guilford Publications, New York, United States.

Swift V. Dickson, James, E.L, Kippen, S., Liamputtong (2007). Doing Sensitive Research: What Challenges Do Qualitative Researchers Face? Qualitative Researcher, voI.7.no.3.327-353.

Taylor, Steven and Bogdan, Robert (1984).Introduction to qualitative research Methods (2nd Ed) New York: Wiley.

Walls, Patricia. G. (2011): Socio-cultural challenges in conducting ethnographic research among Ethiopian street youth, The Qualitative Report, Volume 16, Number 3, 848-859 http://www.nova.edu/ssss/QR/QR163/walls.pdf

Wang, Fei (2013): Challenges of Learning to Write Qualitative Research: Students' Voices. Internathional Journal of Qualitative Method. UNIVERSITY OF ALBERTA: INTERNATIONAL INSTITUTE FOR QUALITATIVE METHODOLOGY, P.P - 638- 651.

Webster. (1999). New world Dictionary, N.Y, Warner Book.INC.

Zikmund, W. (2000). Business research methods, 6th Edition. Fort Worth, TX: Dryden Press, P: 214. 